\title{
Review \\ Digitalizalization in Food Supply Chains: A Bibliometric Review and Key-route Main Path Analysis
}

\author{
Abderahman Rejeb ${ }^{1}$, Karim Rejeb ${ }^{2}$, Alireza Abdollahi ${ }^{3}$, Suhaiza Zailani 4, *, Mohammad Iranmanesh 5 , and \\ Morteza Gobakhloo 6,
}

1 Doctoral School of Regional Sciences and Business Administration, Széchenyi István University, 9026 Győr, Hungary; abderrahmen.rejeb@gmail.com

2 Faculty of Sciences of Bizerte, University of Carthage, Zarzouna, Bizerte 7021, Tunisia; karim.rejeb@fsb.ucar.tn

3 Department of Business Administration, Faculty of Management, Kharazmi University, Tehran 1599964511, Iran; abdollahi.alirez@gmail.com

4 Department of Operations Management and Information System, Faculty of Business and Accountancy, University Malaya, Kuala Lumpur 50203, Malaysia; shmz@um.edu.my

5 Senior Lecturer, School of Business and Law, Edith Cowan University, Joondalup, WA Australia, m.iranmanesh@ecu.edu.au

6 Senior Lecturer, School of Economics and Business, Kaunas University of Technology, Kaunas, Lithuania, morteza.ghobakhloo@ktu.lt

* Correspondence: shmz@um.edu.my

\begin{abstract}
Technological advances such as blockchain, artificial intelligence, big data, social media, geographic information systems represent a building block of the digital transformation that supports the resilience of the food supply chain (FSC) and increases its efficiency. This paper reviews the literature surrounding digitalization in FSCs. A bibliometric and key-route main path analysis was carried out to objectively and analytically uncover the knowledge development in digitalization within the context of sustainable FSCs. The research began with the selection of 2140 articles published nearly over five decades. Then, the articles were examined according to several bibliometric metrics such as year of publication, countries, institutions, sources, authors, and keywords frequency. A keyword co-occurrence network was generated to cluster the relevant literature. Findings of the review and bibliometric analysis indicate that research at the intersection of technology and the FSC has gained substantial interest from scholars. On the basis of keyword co-occurrence network, the literature is focused on the role of information communication technology for agriculture and food security, food waste and circular economy, and the merge of the Internet of Things and blockchain in the FSC. The analysis of the key-route main path uncovers three critical periods marking the development of technology-enabled FSCs. The study offers scholars a better understanding of digitalization within the agri-food industry and the current knowledge gaps for future research. Practitioners may find the review useful to remain ahead of the latest discussions of technology-enabled FSCs. To the authors' best knowledge, the current study is one of the few endeavors to explore technology-enabled FSCs using a comprehensive sample of journals articles published during the past five decades.
\end{abstract}

Keywords: Agri-Food, Food Supply Chain, Blockchain, IoT, Big Data, Sustainability, Food Security, COVID-19, Food Safety, Digitalization

\section{Introduction}


The food supply chain (FSC) plays a critical role in the world economy [1] and has been one of the crucial pillars of human civilization throughout history [2,3]. It refers to the chain starting from the raw materials in agriculture to the process of production and product distribution and the linkages between them [4,5]. From the definition, it appears that the FSC encompasses all the stages regarding the supply, production, and consumption of a food product. Scholars have voiced the need to transform the traditional FSC for several reasons. The supply chain has to feed 9.7 billion in 2050 compared with 7.8 billion today [6]. This enormous increase should be addressed in all the stages of the process. Furthermore, as agriculture is the most prominent source of food globally, water consumption is expected to rise dramatically and pose a sustainability issue $[3,7,8]$. The greenhouse gas emission, climate change, the increasing consumption of fertilizers and pesticides, and other resources, and the pollution due to production, distribution, and logistics stages are among other environmentally damaging consequences of such an increase [9-11]. In addition, there are debates about the safety, quality, and security of food products which call for enhancements in traceability and transparency of the FSC $[12,13]$. Additionally, the perishable nature of food products and food loss throughout the FSC compels academia and industry to improve real-time monitoring and traceability capabilities [14,15].

A promising solution to the abovementioned challenges is incorporating cuttingedge technologies. The digitalization of the FSC has been considered a necessity to achieve sustainable competitive advantage and decrease value chain risks [16-19]. Various scholars have investigated various technologies to contribute to the digital transformation of the FSC. Incorporating the Internet of Things (IoT) [20-24], blockchain technology [2527], big data [20,28,29], wireless sensor networks (WSN) [30,31], artificial intelligence (AI) techniques [32-36], computing technologies [28,37-39], geospatial technologies [40], radio frequency identification (RFID) $[26,41]$, and remote sensing technologies such as drones $[42,43]$ are among these innovative endeavors.

Since research on the technology-enabled FSC has witnessed considerable growth during the last two decades, the need for structured reviews based on quantitative methodologies is urgent to summarize the field and reveal the conceptual structure of the knowledge domain [44]. In the extant literature, the efforts mostly have been placed on examining and summarizing the intersection of a specific technology and a limited part of the supply chain, such as Industry 4.0 technologies and agriculture [45], WSN and agriculture intersection [46], IoT and FSC dynamics [47,48], IoT and food safety [49], IoT, data analytics, and agriculture [7], distributed ledger technology and the FSC [50], blockchain and FSC traceability [51], IoT, big data, AI and FSC domain[52], IoT and quality management in the FSC [48], blockchain and agri-food industry or FSCs [53,54], and big data and food safety [55]. Although all these endeavors have provided fruitful insights into the opportunities and challenges of new technologies in the food sector, none has investigated the entire field of technology-enabled FSCs from a holistic perspective. A few studies summarized the technology-enabled supply chain domain, including [56], who reviewed the fresh fruit and vegetables supply chain literature from the resourcebased view perspective and identified several potential opportunities and weaknesses of ICT technologies as firm resources. Similarly, [57] surveyed economic, environmental, social, functional, and technological impacts and challenges of four important agri-food 4.0 technologies, namely IoT, big data, AI, and blockchain in FSC application. These studies also provide an increased understanding, nevertheless, none investigated the field based on a quantitative structured methodology like bibliometrics to visualize the knowledge domain and reveal the big picture.

To fill this gap, we conduct a bibliometric and key-route analysis to examine the knowledge surrounding the technology-enabled FSC. By doing so, this study provides academics and business practitioners significant insights into the trajectories and evolution of the technology-enabled FSC knowledge domain. Various research paradigms and foci discussed in the field from different perspectives could be better identified. The 
study also reveals the most influential papers, authors, sources, and countries. By identifying and presenting the current status, research gaps, future research directions of technology-enabled FSCs, this study can contribute to academia and industry. In our journey, we are guided by the following research questions:

- What are the dynamics between technology and the FSC in the reviewed publications?

- What technologies are being adopted to improve the FSC?

- How are various technologies being adopted in the FSC?

- What are the current research gaps at the intersection of technology and the FSC?

The remainder of the paper is structured as follows. Section 2 presents the research methodology, including the bibliometric approach, the key-route main path method, and the data gathering strategy. Section 3 discusses the main findings of descriptive analysis, followed by the results of the keywords co-occurrence network and key-route main path analysis in section 4 . Finally, section 5 concludes and provides research implications, limitations, and future directions.

\section{Research Methodology}

\subsection{Bibliometric Method}

Since the primary objective of this review is to examine the current knowledge technology-enabled FSCs, we conducted a bibliometric and key-route main path analysis. Unlike traditional reviews, bibliometric reviews represent a systematic analytical tool that helps researchers determine the most influential authors, their affiliations, the keywords they selected, and the interrelationships between their works [58]. The use of bibliometrics is suitable when investigating the current status of a particular research field using various indicators, including influential authors, journals, countries, and academic institutions. With the support of bibliometrics, researchers would be able to identify levels of research collaborations among authors, institutions, and countries. The bibliometric approach ensures a transparent, objective, and systematic representation of research [59]. This research method has been commonly applied in the prior literature to analyze a high volume of publications in diverse fields and domains such as green supply chain management [60], sustainability [61,62], blockchain technology [63,64], and halal food [6567].

This review draws on bibliometric analysis as the appropriate tool to investigate the existing knowledge based on which the interplay between technologies and sustainable FSCs is founded. As part of this focus, we performed a keyword co-occurrence network analysis to gain an in-depth understanding of this topic. A keyword co-occurrence network analysis reveals that author-supplied keywords co-occur, and it depicts the relationships between them. According to [68], this network analysis enables researchers to identify research topics and understand the transition of research frontiers in a specific scientific field. In the keyword co-occurrence network, two keywords are closely related if they appear in the same publications more frequently. By producing the keyword cooccurrence network, we aspired to analyze the core content from the used keywords and assess the research structure at the intersection of technologies and sustainable FSCs. The visual tool chosen for generating this network was VOSviewer due to its high compatibility with the BibExcel software. Density was used to measure the strength of association between keywords [69]. In VOSviewer, VOS mapping allows researchers to obtain a map of nodes for keywords and the distance between each pair of keywords based on density [70]. The general idea of the algorithm is to minimize the weighted sum of squared Euclidean distance between each couple of keywords in an iterative process [71]. Accordingly, the nearer the distance between two keywords, the higher is the density value. 


\subsection{Key-route Main Path Analysis}

To supplement the keyword co-occurrence network, we conducted a key-route main path analysis to examine the knowledge diffusion routes and understand the historical development of technology-enabled sustainable FSCs. In a citation-link network, as shown in Figure 1, the search path count (SPC) of a link constitutes the total number of times that a link is traversed if one exhausts the search from all node sources (i.e., nodes that are only cited while referring to no other nodes) to all sink nodes (i.e., those that are not cited by other nodes but only cite other nodes) in the citation network. For example, the SCP of the link C-D is four because only four paths pass through this link, namely, AC-D-G, A-C-D-H, B-C-D-G, and B-C-D-H, C. However, the search path link count (SPLC) is another way of measuring the importance of a link, consisting of the number of times one link is traversed if one runs through all possible paths from all earlier nodes to all sink nodes [72]. For example, the SPLC of the link C-D is six because six paths pass through this link (including the starting node C), namely, A-C-D-G, A-C-D-H, B-C-D-G, B-C-DH, C, C-D-G, and C-D-H. Because intermediate nodes (e.g., C) pass and generate knowledge [73], the SPLC is chosen to weight the citation network and reflect the current knowledge diffusion situation.

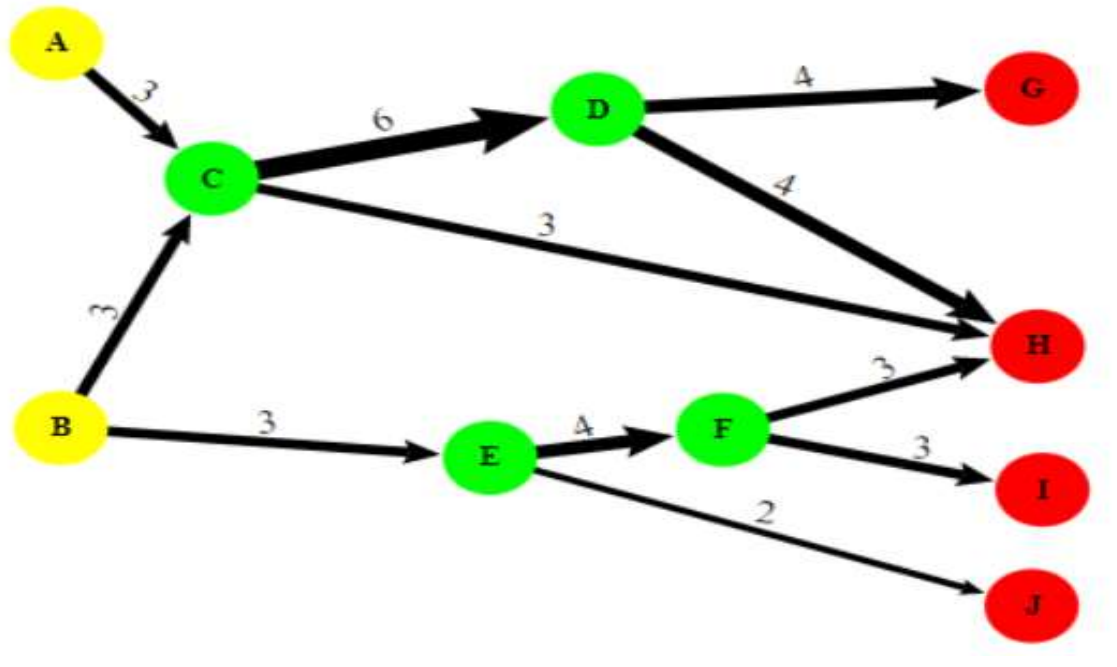

Figure 1. A typical citation network weighted with SPLC values

According to [74], the key-route search process starts with the link with the highest traversal weight and then searches forward from the end node of the link until a sink node is reached; and search backward from the beginning node of the link until a source is reached. The resulting path-fragments are coupled together to construct the key-route main path. The more key-routes are chosen, the more details and information about the main path are revealed. Therefore, the key-route main path is preferred in this study to capture prior knowledge and most significant links in the main path [74].

To simplify understanding, the key-route main path generated from Figure 1 is presented in Figure 2. Since the link C-D has the largest SPLC value, it is chosen as the citation link, which plays an important role in the knowledge diffusion procedure. When searching forward and backward from the link C-D, the key-route main path is obtained and shown in Figure 2. 


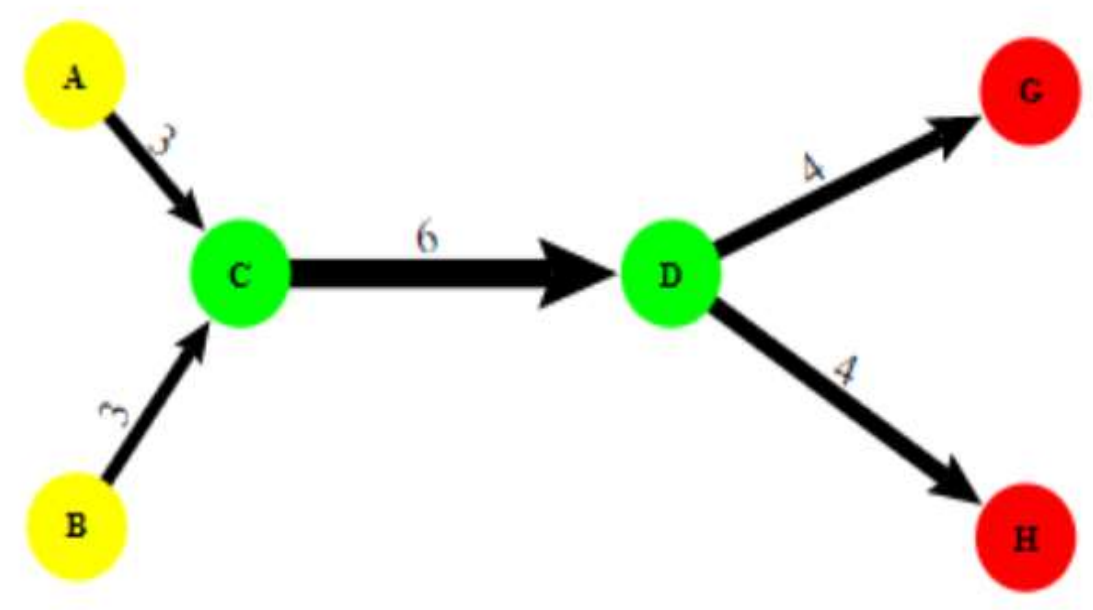

Figure 2. The key-route main path from the typical citation network

\subsection{Data Collection}

For our study, data from the Scopus database was retrieved. Scopus represents a world-leading repository widely recognized for its comprehensive coverage and reliable content, containing a large number of publications published in journals provided by premier publishers such as Elsevier, EmeraldInsight, Springer, and Taylor and Francis $[75,76]$. The search string used was the following: ( "food" OR "agri-product" OR "agri-food" OR "agriculture" ) AND ( "Sustainab" OR "environ*" OR "Green" OR "eco*" OR "Social" OR "Societal" OR "CSR" ) AND ("Supply chain" OR "Value Chain" OR "Logistics" ) AND ( "Digi*" OR "Information Syst" ${ }^{*}$ OR "techno*" OR "big data" OR "data analy" OR "Business Intelligence" OR "Artificial Intelligence" OR "Social Media" OR "Internet of Things" OR "Blockchain" ). The search was carried out in the title, abstract, and keyword fields. To maintain the academic nature and high quality of the literature, the search was only limited to peer-reviewed English-speaking journal articles. The authors screened the titles and abstracts of these articles, excluding all publications with missing bibliometric data (e.g., abstracts, keywords). As a result, 2140 documents were retrieved from Scopus in .txt and CSV formats for the final analysis using the visual tools VOSviewer and Pajek.

\section{Results of the Descriptive Statistics}

\subsection{Publications by Year}

Figure 3 shows the annual distribution of journal articles, showing a consistently growing trend since 1975. In the first two decades (1975-1995), the literature appears scarce, with less than four papers each year. These two decades may be referred to as the initial stage in research on technology-enabled FSCs. The following two decades (19962015) witnessed increased attention toward the topic, as demonstrated by the slight increase in the number of publications. This stage can be designated the initial growth stage. The subsequent five years (2016-2021) are featured by a rapid increase in research interest in the topic of technology-enabled FSCs. This stage can be named the exponential growth stage since it observes the most significant growth rate during the study period. 


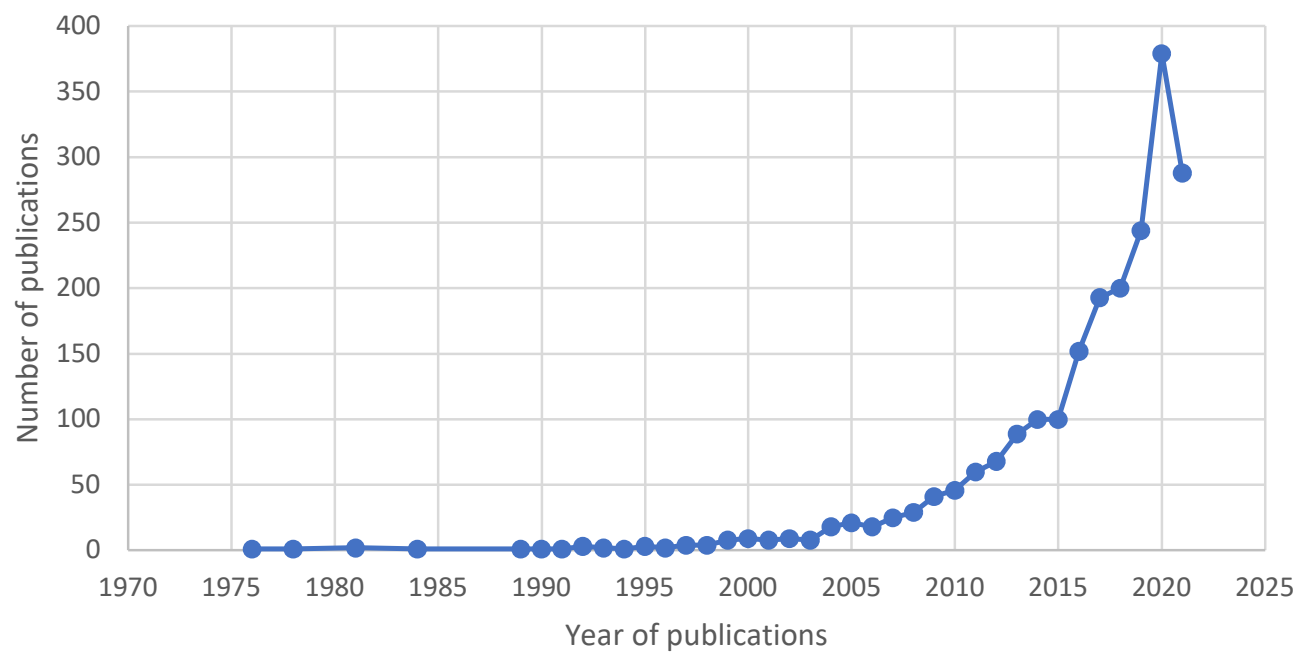

Figure 3. The year-wise distribution of publications

\subsection{Publications by Country}

Table 1 shows the distribution of publications according to countries. As can be seen, the highest number of publications (509) originated in the USA, followed by the United Kingdom (270), China (179), Italy (166), and India (152). Summarizing, research on technology-enabled FSCs has been carried out worldwide, even though there is a high concentration of scholarly output in developed countries. North America and Europe contributed significantly to the literature, ranking higher than Asia; meanwhile, African countries are not included in the list. Although this may call for increasing research cooperation, it should be mentioned that only English-speaking publications were selected for this review.

Table 1. Top 20 contributing countries

\begin{tabular}{ll}
\hline Country & $\begin{array}{l}\text { Number of } \\
\text { publications }\end{array}$ \\
\hline United States & 509 \\
United Kingdom & 270 \\
China & 179 \\
Italy & 166 \\
India & 152 \\
Australia & 113 \\
Canada & 110 \\
Netherlands & 106 \\
Germany & 100 \\
Spain & 84 \\
France & 69 \\
Brazil & 65 \\
Belgium & 56
\end{tabular}




\begin{tabular}{ll} 
South Africa & 46 \\
Switzerland & 46 \\
Greece & 43 \\
Sweden & 42 \\
Denmark & 41 \\
Kenya & 40 \\
Malaysia & 40 \\
\hline
\end{tabular}

\subsection{Publications by institutions}

Table 2 depicts the top 20 academic institutions contributing the most to research pertaining to technology-enabled FSCs. The affiliation with the highest number of publications is Wageningen University \& Research with 68 publications, followed by Michigan State University with 25 publications and Universiteit Gent with 19 publications. In general, the list of top ten productive institutions does not contain institutions located in developing nations. Although research on technology-enabled FSCs disperse worldwide, the low research productivity of academic institutions belonging to developing nations may partially be justified by the insufficient cooperation between countries, specifically between scholars of developing and developed nations. The lack of technological infrastructure and resources may be another reason for the digital gap between these nations.

Table 2. Top 10 most relevant institutions

\begin{tabular}{lc}
\hline Institution & Number of publications \\
\hline Wageningen University \& Research & 68 \\
Michigan State University & 25 \\
Universiteit Gent & 19 \\
Cornell University & 18 \\
Imperial College London & 18 \\
University of Minnesota Twin Cities & 17 \\
University of Saskatchewan & 16 \\
Texas A\&M University & 16 \\
INRAE & 15 \\
Universität Bonn & 14 \\
Alma Mater Studiorum Università di Bologna & 14 \\
\hline
\end{tabular}

\subsection{Publications by Journals}

Table 3 shows the top 20 relevant journals publishing articles on technology-enabled FSCs. Overall, these journals published 466 articles, representing $19 \%$ of the 2460 publications that were included in our sample. Journal of Cleaner Production tops the list with 88 articles. Following closely, Sustainability published 85 articles, Plos One 29 articles, and British Food Journal 25 articles. The journal-wise distribution of the scholarly output reflects the distribution suggested by Bradford's law, which suggests that there is a small group of main journals that account for an important percentage of articles on that discipline or subject [77]. Furthermore, the scope of these journals draws upon several 
research areas and topics, including sustainability, food science, environmental science, agriculture, and computer science. As a result, articles published in these journals mirror the diversity, richness, and multidisciplinary nature of technology-enabled FSC research.

Table 3. Top 20 most relevant journals

\begin{tabular}{lc}
\hline Journal & $\begin{array}{c}\text { Number of } \\
\text { publications }\end{array}$ \\
\hline Journal of Cleaner Production & 88 \\
Sustainability & 85 \\
Plos One & 29 \\
British Food Journal & 25 \\
International Journal of Environmental & Re- \\
search and Public Health & 22 \\
Science of the Total Environment & 22 \\
Computers and Electronics in Agriculture & 19 \\
Food Policy & 16 \\
Biomass and Bioenergy & 14 \\
IEEE Access & 14 \\
International Journal of Supply Chain Manage- & 14 \\
ment & 14 \\
Journal of Environmental Management & 14 \\
Resources Conservation and Recycling & 14 \\
Trends in Food Science and Technology & 13 \\
Agricultural Systems & \\
International Food and Agribusiness Manage- & 13 \\
ment Review & 13 \\
International Journal of Production Economics & 13 \\
Renewable and Sustainable Energy Reviews & 12 \\
BMC Public Health & 12 \\
Nutrients &
\end{tabular}

\subsection{Most Productive Authors}

Table 6 depicts the most prolific authors with five publications or more. According to the data, Hobbs ( 8 articles) and Mangla ( 7 articles) dominated the list of publications. Other productive authors include Beulens ( 6 articles), Kamble (6 articles), Rahimifard (6 articles), and Shah (6 articles).

Table 6. Most productive authors with 5 or more publications

\begin{tabular}{lcc}
\hline Author & Number of publications \\
\hline Hobbs, J.E. & 8 \\
Mangla, S.K. & 7 \\
Beulens, A.J.M. & 6 \\
Kamble, S.S. & 6 \\
Rahimifard, S. & 6 \\
Shah, N. & 6 \\
Barrangou, R. & 5
\end{tabular}


Engelseth, P. $\quad 5$

Freidberg, S. $\quad 5$

Gunasekaran, A. 5

Luthra, S. $\quad 5$

Mishra, N. $\quad 5$

Raut, R.D. 5

Reardon, T. $\quad 5$

Sarkis, J. $\quad 5$

Singh, A. $\quad 5$

\subsection{Keyword Frequency Analysis}

Table 7 shows the 20 most frequent keywords. Because of increasing consumer awareness and higher resource consumption, food industry stakeholders must achieve sustainable consumption and production by coordinating and optimizing their FSC operations [78]. The integration of sustainability and the FSC is an evolving research area that has given rise to new methods and practices of managing food systems over the last recent decades [79]. For example, [80] noted the role of information and communication technologies (ICT) in agricultural production to maximize agricultural yield and support farms to be more productive, thereby increasing food security. Most frequently used keywords include "IoT" and "Blockchain." In recent years, IoT has had great potential for application in the domain of food and agriculture as the technology can facilitate traceability from farm to fork, contribute to food safety, and reduce agricultural inputs and food waste [81]. Several studies emphasize the abilities of IoT to support real-time information collection and sharing, augment FSC sustainability, and reduce issues related to food quality and safety [82-85].

Combined with IoT, blockchain can overcome several traceability issues and improve FSC transparency because it is plausible to keep data from chemical analysis in chronological order, thereby eliminating data manipulation and falsification [86]. From the supply chain and logistics perspective, blockchain has been praised for its visibility, immutability of transactions, and its trustworthiness among participating stakeholders [87]. The keyword "GIS" (geographic information systems) appears frequently, implying that the development of GIS brings several opportunities to FSCs as they enable to monitor and control crop growth at a very precise level [85]. Furthermore, the trend of digitization in the FSC has been reinforced by the 2019 coronavirus (COVID-19) pandemic [88], which has altered the attitude of food consumers and laid bare several logistical issues in FSCs such as rising food demand, supply disruption, and lack of FSC resilience [89]. Facing the challenges posed by the COVID-19 pandemic, the existing linear systems of production and consumption are deemed unsustainable as finite natural resources are substantially used to produce and distribute foods. For this reason, several scholars have advocated positive outcomes from the implementation of circular economy strategies, including food waste reduction, increased environmental sustainability, and promotion of sustainable and resource-efficient policies [90-92]. Overall, all the keywords listed in Table 7 suggest the practicality of technology-enabled FSCs to optimize operational efficiencies, mitigate disruptions, and ensure sustainability in the agri-food industry.

Table 7. Top 20 most frequent keywords in technology-enabled FSCs research

\begin{tabular}{ll}
\hline Keyword & Frequency \\
\hline Sustainability & 143 \\
SC & 116 \\
Agriculture & 82 \\
FSC & 81
\end{tabular}




$\begin{array}{ll}\text { IoT } & 70 \\ \text { Food Security } & 67 \\ \text { Blockchain } & 63 \\ \text { Food Waste } & 60 \\ \text { SCM } & 58 \\ \text { LCA } & 56 \\ \text { GIS } & 55 \\ \text { Food Safety } & 48 \\ \text { Value Chain } & 47 \\ \text { Innovation } & 46 \\ \text { Food Industry } & 46 \\ \text { Traceability } & 44 \\ \text { Logistics } & 43 \\ \text { Coronavirus } & 40 \\ \text { ICT } & 32 \\ \text { Circular Economy } & 32\end{array}$

\section{Results from Bibliometric and Key-route Main Path Analysis}

\subsection{Keyword Co-occurrence Network Analysis}

The keyword co-occurrence network is used to identify "keywords" that co-occur in at least two publications in a time span [93]. This scientometric method enables to generate clusters that provide a broader view of different research foci in a specific knowledge domain [94]. To obtain the network, we began by extracting all keywords from each publication. We pretreated and harmonized the keywords to maintain consistency. For instance, keywords are written in full length (e.g., food supply chain, internet of things, big data analytics, information and communication technologies) were abbreviated. The appearance of two keywords within the same publications indicates the association between topics to which they relate [95]. The keyword co-occurrence network analysis helps scholars to detect the core content of the literature and depict the structure of a knowledge domain. Therefore, to obtain the network, the data were loaded into VOSviewer, and the density-based spatial clustering based on the full counting method was used [96]. Since the suitable number of keywords in the network varies from 200 to 500 [97], the occurrence of keywords appearing in the network was set to be 8 . As a result, five clusters with distinct colors were generated, as shown in Figure 4 and detailed in Table 8. A node constitutes a keyword, and the node size corresponds to the co-occurrence frequency of the keyword. The distance between two keywords in the visualization is determined by density, and the higher this density, the closer is the distance between two nodes [98]. 


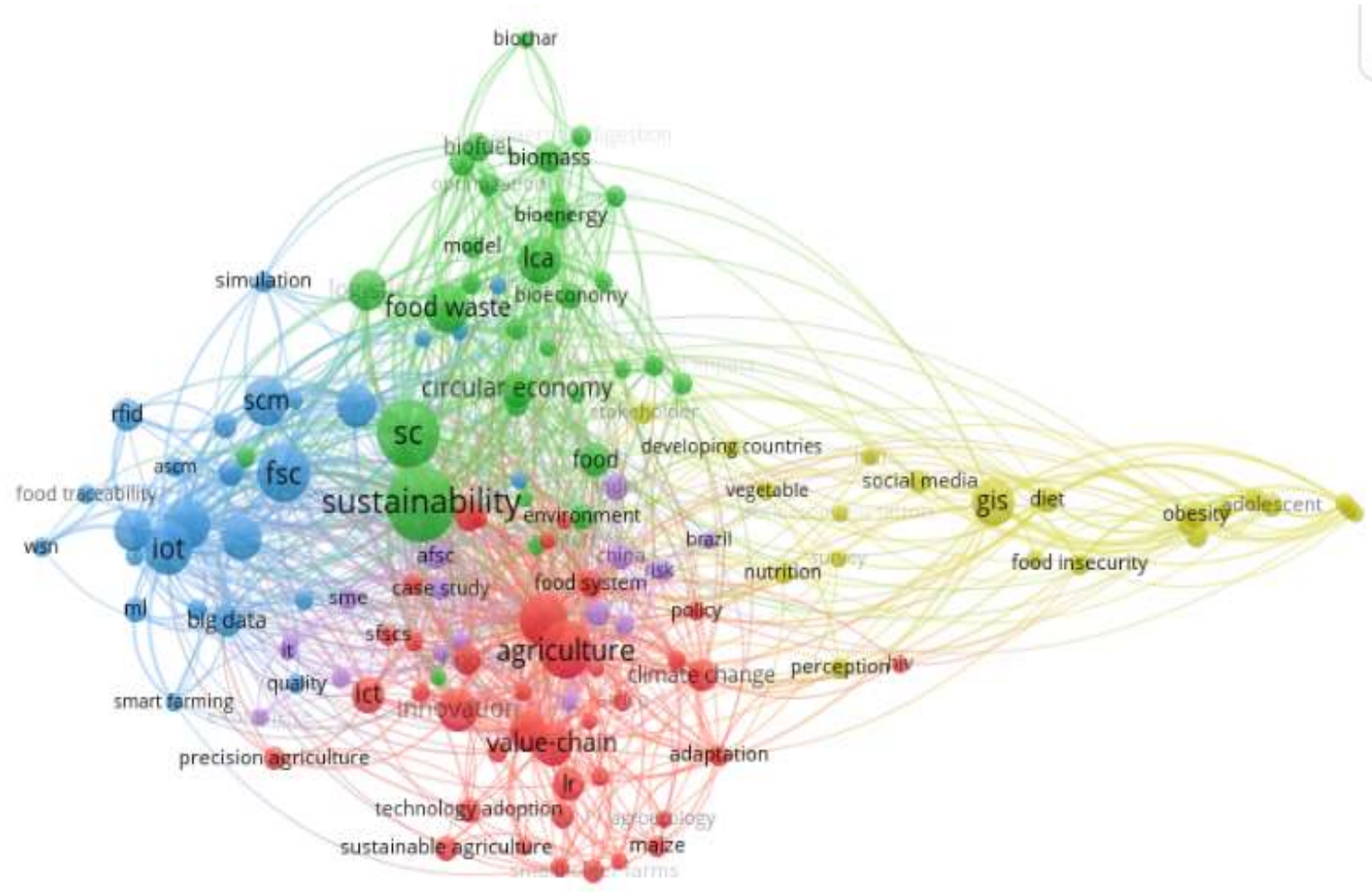

Figure 4. Keyword co-occurrence network

Table 8. Most frequently keywords based on keyword co-occurrence clustering

\begin{tabular}{|c|c|c|}
\hline Cluster & Theme & Most frequent keywords \\
\hline 1 & $\begin{array}{l}\text { ICT for } \\
\text { agriculture and } \\
\text { food security }\end{array}$ & $\begin{array}{l}\text { Agriculture; food security; value-chain; innovation; coronavirus; ICT; } \\
\text { LR; climate change; SDGs; technology; food system; technology } \\
\text { adoption; precision agriculture }\end{array}$ \\
\hline 2 & $\begin{array}{l}\text { Food waste and } \\
\text { circular } \\
\text { economy }\end{array}$ & $\begin{array}{l}\text { Sustainability; SC; food waste; LCA; logistics; circular economy; food; } \\
\text { biomass; biofuel; bioeconomy; bioenergy; biofinery; environment; food } \\
\text { loss }\end{array}$ \\
\hline 3 & $\begin{array}{l}\text { IoT and } \\
\text { blockchain in } \\
\text { FSCs }\end{array}$ & $\begin{array}{l}\text { FSC; IoT; blockchain; SCM; food safety; traceability; big data; RFID; } \\
\text { Industry 4.0; ML; AI; simulation; transparency; WSN; cold chain; } \\
\text { integration }\end{array}$ \\
\hline 4 & $\begin{array}{l}\text { GIS and } \\
\text { consumer } \\
\text { perceptions }\end{array}$ & $\begin{array}{l}\text { GIS; diet; obesity; adolescent; children; risk factor; social media; fast- } \\
\text { food; nutrition; stakeholder; food insecurity; perception; vegetable; built } \\
\text { environment; physical activity }\end{array}$ \\
\hline 5 & $\begin{array}{l}\text { Indian and } \\
\text { Chinese AFSCs }\end{array}$ & $\begin{array}{l}\text { AFSC; India; agribusiness; China; case study; SME; consumer; decision } \\
\text { making; biotechnology; IT; risk; Brazil; agricultural product; e- } \\
\text { commerce; entrepreneurship }\end{array}$ \\
\hline
\end{tabular}




\subsubsection{ICT for Agriculture and Food Security}

Table 8 demonstrates that cluster 1 focuses on the contributions of ICT and innovation to food security and sustainable development goals, and thus we labeled it as ICT for agriculture and food security. Examples of the most relevant keywords in this cluster are "agriculture," "food security," "innovation," and "ICT". According to the Food and Agriculture Organization (FAO), food security is achieved "when all people, at all times, have physical, social, and economic access to sufficient, safe and nutritious food which meets their dietary needs and food preferences for an active and healthy life" . This conceptualization emphasizes two critical elements; (1) food availability and access and (2) food quality and safety.

As a complex and multidimensional concept, food security is an issue that needs to be urgently addressed due to the exponential rise in the world population, which is estimated to reach 9.6 billion in 2050 [99]. In this context, [100] argued that "value-chain agriculture" constitutes a potential solution to incorporate smallholding farmers into commercial relationships to overcome food shortages. The objective of value-chain agriculture is to increase market connection and agriculture productivity as well as maximize the ecological and economic value-generating potential of farmers. Moreover, policy objectives like food security and sustainable development goals (SDGs) can be realized by the promotion of innovation and the adoption of new information communication technologies (ICT) [85]. [101] notes a need to reorientate food innovation systems towards sustainability and equality by maximizing crop yields and inputs quality. Similarly, [102] posit that an innovation-based approach among food industry stakeholders can improve food security, simplify access to markets, fight poverty and malnutrition, and boost sustainable natural resource management.

While technological innovations are imperative, FSCs still encounter food insecurity and climate change. Agriculture is an important sector in greenhouse gas (GHG) emissions and continually struggles to mitigate climate change by limiting GHG emissions [103]. Excessive consumption of resources (e.g., land, water, energy, pesticides, fertilizers, etc.) can degrade the environment, accelerate deforestation, and worsen climate change [104]. In addition, exposure to high temperatures can stress the physiological, morphological, and metabolic processes of agriculture crops and deteriorate the quality attributes of food products [105]. However, the continuous instrumentalization of agrifood activities provides farmers with a wealth of novel data-driven services [81] and propels smart farming or precision agriculture [85]. This decisive phenomenon enables to improve farming processes in terms of efficiency, automation, and environmental concerns [106]. Integrating multiple ICTs, precision agriculture fosters agri-food sustainability transition by optimizing resource productivity, overcoming inefficiencies, reducing management costs, and streamlining food chain coordination [107].

While the literature on the possibilities of ICTs in agriculture and food security is abundant, there is still a need to comprehend how sustainability goals can be embedded into the development of technology-enabled agricultural processes and products [108]. The investigation of the ways to maintain food security and balance economic, environmental, and social sustainability by adopting new technologies is another promising avenue for future research as all policymakers and government bodies across the globe are placing food security on the top of their political agenda [109]. As an alarming threat to the agriculture industry, climate change perceptions among FSC stakeholders should be examined in order to motivate practices and technologies that lower agriculture's side effects and mitigate climate change. Finally, scholars should draw upon the domain's wealth of current knowledge to clarify how precision agriculture can not only offer noticeable benefits to farmers but also concurrently improve resource management and conservation to meet sustainability requirements. 


\subsubsection{Food Waste and Circular Economy}

Food systems depend heavily on natural resources such as land, soil, and water. An enormous amount of inputs like pesticides, fertilizers, energy, and human labor are employed in production, processing, transportation, distribution, and storage processes to deliver food products for human consumption. As a result, food waste represents a waste of land, water, inputs, non-value-adding activities, and unnecessary factors contributing to climate change [91]. Keywords such as "sustainability," "food waste," "LCA" (lifecycle assessment), and "circular economy" are therefore included in this cluster. From the environmental and food security perspective, food waste is a key aspect for sustainable development, which requires implementing different food reduction measures to achieve sustainability $[99,110,111]$.

According to [111], LCA can be used to model food waste because it is an appropriate tool to assess technological and managerial solutions to dysfunctional FSCs. LCA provides information to consumers and other primary stakeholders in the food industry on the environmental impact of food products, thus increasing food chain transparency and traceability [112]. In a circular economy, LCA also can environmentally assess food products or circular FSC business models by offering improved ideas to circular FSC solutions [113]. For example, the evaluation of waste management, including logistics, can be facilitated with LCA implementation in a circular economy by reducing fertilizer consumption, improving waster-efficiency measures, and optimizing management along the whole FSC to limit food waste and losses during production and distribution [111]. In the frame of circular economy, [114] contended that agri-food products would have significant potential as the circular economy approach enables farmers to reduce environmental and economic costs caused by food waste disposal. The joint application of circular economy and bioeconomy in the food industry is expected to provide ecoefficient production of renewable food and energy efficiency, thereby responding to the basic needs of consumers [115]. The conversion of produced biomass such as crops and organic waste materials into bio-based products like biofuels and bioenergy could balance and limit fossil energy use and satisfy primary energy demands [116].

From the discussion of this cluster, it appears that there is still ample room for investigating how the circular economy is taking form and operating in today's food systems to achieve sustainable development [117]. To date, for example, few studies exist to demonstrate a practical approach to implement the circular economy and bioeconomy concepts in the FSC. The lack of practical use cases undermines the ability of food organizations to devise appropriate strategies and policies in favor of circular FSC business models. A contribution opportunity from future research would be to clarify how LCA can support the decision-making processes of food organizations throughout the different stages of a circular bioeconomy model. In spite of the increasing interest in circularity practices, there is a paucity of research that showcases new strategies aimed at reusing or recycling food materials through innovative technologies and solutions. Therefore, the examination of the contextual factors that determine the adoption of emerging technologies in reducing food waste and transitioning toward the circular economy is required. As such, the comprehension of the organizational objectives, activities, and environment can help practitioners identify the adequate business context in which circular economy principles can be implemented in the FSC. Further discussion is also required to understand how circular FSCs outperform linear FSCs not only in terms of environmental performance but also in terms of economic and social sustainability. 


\subsubsection{IoT and Blockchain in FSCs}

The blue cluster revolves around the role of IoT and blockchain in increasing FSC efficiency, transparency, and traceability. Because of the more highlighted role of IoT and blockchain in the extant literature compared to other technologies, we labeled the cluster as IoT and blockchain in FSCs. It is also evident from most relevant keywords including "FSC", "IoT", "blockchain", "SCM", "food safety", "traceability", "transparency", and various technologies investigated by scholars to revolutionize the FSC. Traditional FSCs have faced multiple food safety and security issues due to incomplete and asymmetric information, thus requiring innovative solutions to enhance FSC traceability and transparency [12,118-120]. The issue becomes evident considering the cold chain and COVID19 pandemic [13]. IoT is considered a paradigm shift in supply chain management [21,47] and FSC specifically [7,121]. Its enabling role in integrating cyber and physical worlds and various technologies such as WSN, RFID, big data, and AI techniques (e.g., machine learning) equipped the FSC with high business intelligence to improve decision making, achieve economic and sustainable goals, and provide food safety and FSC transparency $[7,122]$.

To be more specific, in the first phase, a huge amount of data (e.g., humidity, temperature, soil moisture, etc.) is extracted by sensor nodes from the field. The data is then transferred to the base station after minor processing. More in-depth processing is done by conducting big data analytic methods and AI techniques to provide helpful information for site-specific management and precision farming [3,7,8,122]. Additionally, IoT could simplify the upstream and downstream parties' collaboration. All the companies across the supply chain could benefit from the integrated near real-time data and analytics that IoT devices provide [13]. In the next phase of the supply chain, IoT devices measure, analyze, and store various data from raw materials purchasing, production, transportation, shipping, and warehousing conditions, among other parts of the food logistics. For example, various conditions such as temperature, time, humidity, product life cycle, and location history in different stages could be extracted by various sensors (e.g., geospatial technologies, RFID, near-field communication (NFC), temperature sensors, and humidity sensors) and analyzed by computing technologies, big data, AI, etc. [17,53,122,123]. The task of data and information assignment to the products and also the task of reading or accessing the information could be automated by RFID tags [13]. Due to the abovementioned benefits, the interests of various stakeholders, including supply chain members, the public, and institutions regarding food safety, security, quality, traceability, and transparency could be served simultaneously.

However, central systems and databases may not be suitable for handling FSC data for several reasons [124]. The decentralized nature of IoT encompassing an enormous number of distributed devices indicates the need for scalable decentralized systems [125]. Moreover, centralized systems are more exposed to hacking risks and abuse of power $[125,126]$. Also, consumers usually fail to acquire all needed information and trace the product from its origin [51]. Hence the reliability and information accuracy issues arise [127]. Additionally, a single point of failure may lead to system disruptions [128]. As an emerging technology, blockchain has the potential to solve accessibility, security accountability, and accuracy problems [124]. Blockchain technology offers digital trust, which could be substituted with real-world trust among unreliable parties (e.g., supply chain members) $[128,129]$. It could contribute significantly to the IoT-based supply chain. Blockchain could establish trust as the data usually is stored in time-stamped, tamper-proof, immutable, and chronologically-connected blocks secured with cryptography and distributed in several nodes $[17,51]$. Because the data is distributed and there is no central authority or trusted third party, the data is completely transparent and secure, and the stakeholders could rely on the data provided and trace the product from the very beginning [129-132].

Although they offer huge potentials, IoT and blockchain integration faces several challenges. Empirical research based on successful implementation and good practices is 
scarce [17]. The interoperability and standardization issues are another drawback in successfully adopting the technologies, which offers an exciting pathway for future researchers [51]. Also, there are limitations in achieving scalability, energy efficiency, stability, privacy, and security simultaneously for blockchain-based IoT solutions [50] as more energyefficient and scalable consensus mechanisms and solutions usually face security challenges. Moreover, implementing such systems requires considerable investment [50]. These all indicate the need for developing a new system design or novel distributed ledger technology architecture.

Blockchain regulation is another obstacle [51] that should be addressed in future studies developing frameworks in collaboration with governments, health departments, and other related institutions. At the sensing level, the energy efficiency of IoT devices needs to be addressed. Improving sensors' energy efficiency [50], enhancing power supplies [133], and developing energy-independent sensors [134] are among interesting topics. Furthermore, the connectivity of IoT devices has great potential for upcoming projects. The promising solutions include adopting fog computing, edge computing, and blockchain [124]. As a socio-technological concept, the acceptance and implication of the technologies by supply chain parties and consumers are of great importance and urgent need for related research [124].

\subsubsection{GIS and Consumer Perceptions}

The fourth cluster investigates the technology-enabled FSC from the perspective of consumer behavior and health care. This focus tries to explain the measures for understanding the local environment and the influence of the built environment on health and eating habits. The following keywords strengthen the argument: "GIS", "diet", "obesity", "fast-food", "nutrition", "perception", "vegetable", "built environment", and "physical activity". The importance of diet is undeniable in having a healthy life like diet, and obesity-related diseases like heart disease, diabetes, and cancer are among important causes of premature mortality and preventable deaths [135-138]. Scholars in this cluster investigated and compared the measures for determining the food environment [139-142].

Two of the most used measures include GIS technology $[143,144]$ and perception based on surveys, interviews, etc. [145,146]. The first (GIS technology) has been considered a promising facilitator of studies related to dynamics between health mapping, environmental exposure, and health care changes [136]. The second, or the perception of distance to various food outlets, is a complex phenomenon dependent on different variables such as physical fitness $[147,148]$, the level of socialization and connection with neighbors [149], and the motivation to, for example, buy from a specific neighborhood [150]. On the other hand, the researchers in this cluster examined how the local built environment and food insecurity affect healthy diet and physical activity [151-154]. In other words, the availability of fruits and vegetables, supermarkets, groceries, and fast-foods relation to diet and obesity has been explored. Among others, [145,155-157] reported a positive relationship between the availability of healthy food or positive built environment perception and healthier diet and physical activity.

Considering the empowering role of GIS technology in the built environment and health care studies, researchers need to conduct their studies to expand and enhance GIS applications in the domain and develop GIS data analysis techniques such as the spatial regression method [136,158]. Furthermore, other geospatial technologies could provide promising solutions for the domain. Combining GIS, Global Positioning System (GPS), and Remote Sensing (RS), also known as 3s, could revolutionize the obesity-related research, for example, by measuring the exposure based on GIS and wearable GPS devices, or by including the time of daylight, temperature, and rainfall based on RS technology [158].

Although arduous endeavors have been made to explore objective and subjective neighborhood impacts on a healthier diet, more efforts should be made to understand 
their inter-relationship and what factors modify their relation (e.g., residents' engagement in the local environment) [149]. Also, an under-investigated domain is how to successfully develop health promotion strategies and implement public health interventions to improve the perception of the surrounding environment based on the findings of academic researches $[159,160]$. Moreover, various studies reported other elements that affect healthier diet and food intake such as budget, self-rated health, quality, preferences, acceptance, cultural tailoring, accommodation, and carrying difficulties [158,161-167], and indicated that the real consumption of fast foods might differ exposure rate [154]. These all indicate the need for developing new researches based on different perspectives and contexts to explore what affects a healthier diet. Additionally, as physical activity and healthy food environments are closely related to human physical and mental health, another underresearched pathway for future studies could be exploring both simultaneously instead of considering them isolated [168].

\subsubsection{Indian and Chinese FSCs}

The last cluster revolves around the Indian and Chinese FSC. Both China and India are among the largest producers and exporters of agricultural products, and many lives in both are dependent on agriculture and the food industry due to employment, farming, etc. [169-171]. Also, both have been considered highly emerging economics and markets [172-174]. As with other emerging economies, the governance and population issues are relevant [175]. However, the agriculture sector and FSC in these countries is still traditional due to significant inefficiencies and food wastage $[170,171,176]$, food safety concerns, food security risks, and trust issues [177,178],

Scholars in the current cluster have addressed the problems exploring and examining various areas in the domain, including supply chain integration and collaboration $[169,170,178]$, the effects of macro (e.g., environment and governance structure) and micro (e.g., interpersonal relationships) variables on supply chain information sharing [175]. Oher topics include sustainable growth of small and medium enterprises (SME) and entrepreneurship as the engines of economic development [171,175,179], biotechnology and its enormous potentials for entrepreneurs and agriculture improvement (e.g., grain productivity) [180,181], and the incorporation of cutting-edge technologies such as IoT, blockchain, AI, RFID, etc. to alleviate inefficiencies, improve transparency and traceability, and improve decision making [21,179,182-186]. Technology acceptance by consumers and e-governance [187], sustainability and green practices [188,189], and FSCs during the epidemic crisis, specifically COVID-19 [190] also attract significant attention.

From this paradigm perspective, researchers have identified under-studied research gaps that lead to interesting future topics. The shortcomings in supply chain management in India and China, as well as many other countries, may be caused by the lack of successful implications of academic researches. Future collaboration between researchers and practitioners is needed to address this stage by conducting empirical problem-oriented researches (e.g., identifying the barriers from an empirical perspective) [170]. Additionally, future researchers could compare developed and developing economies and investigate the best practices to be implemented in another context. This could be done, for example, by exploring the institutional context of the countries [175]. Sustainability in the agri-food sector is an understudied subject in developing countries [189]. This could be considered a fruitful future research avenue based on future national and global plans to achieve zero carbon emissions. Furthermore, the food safety and security after the COVID-19 pandemic and increased consumer awareness guide the food industry toward safer no-touch initiatives, which is also a worthy future topic [190]. 


\subsection{Key-route Main Path Analysis}

In order to obtain a broader and more complete view, we further carried out a keyroute main path analysis. Figure 5 depicts the routes produced from the top 26 links in research related to technology-enabled FSCs. We observe that the key-route main paths reveal comprehensive knowledge diffusions in this research field. With the convergence and divergence of paths in the network, the key-route main path tells a wonderful story in the formation of technology-enabled FSC research.

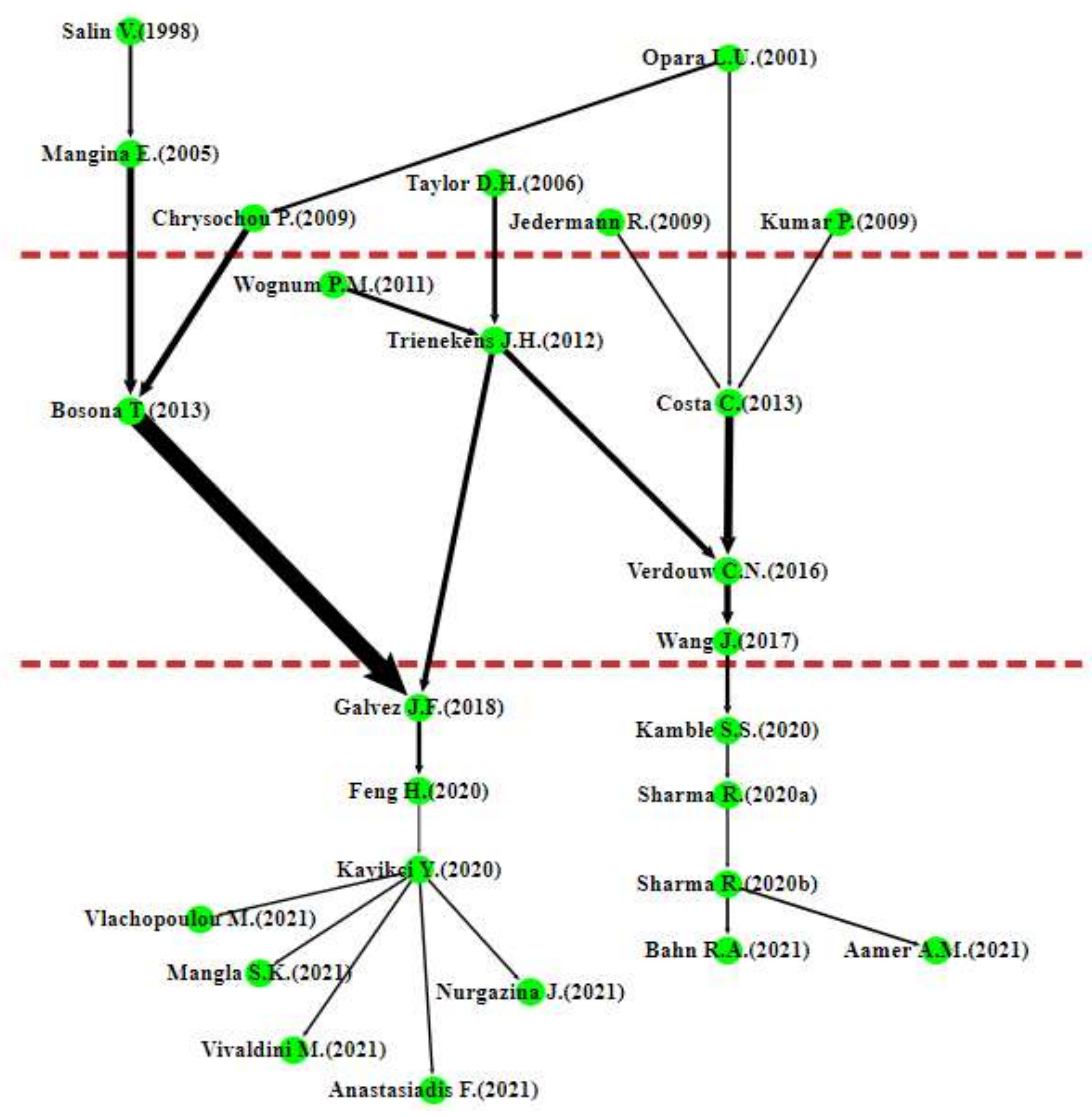

Figure 5. Key-route main path

From years 1998 to 2009, the researchers mainly focused on investigating information technology and RFID applications for food traceability. For example, [191], being the first paper on the key-route main path, marks the initial development of technology-enabled FSC research. In this study, the author explored the distinctions between supply chains for functional vs. innovative products and argued that effective IT systems in the agrifood industry could create information that will offer competitive advantages to the whole food chain, to the degree that information is shared. Later, in response to public concern for food safety, sustainability, animal welfare, [192] presented a worldwide overview of traceability metrics in food trade and explored some of the factors in developing and developed nations. To integrate traceability into current food safety standards and trade agreements, there is a need to invest in IT for data collection, storage, and management. Moreover, [193] provided a model of smart FSC that optimizes efficiency within the supply chain. [194] further noted that consistencies with information systems and data handling processes are essential to maintain alignment of demand and supply in the agrifood industry. In 2009, three papers emerged to study the potential of RFID for food traceability systems. [195] provided fundamental terminologies and concepts related to RFID technology and its use in the agri-food sector. Several applications of RFID are 
highlighted, including supply chain management, temperature monitoring of food products, and food safety; meanwhile, the challenges of deploying the technology are limited read range, read precision, non-interoperable standards, cost, privacy and security concerns, and recycling difficulties. [196] studied how miniaturized RFID temperature loggers can be customized to assess the amount of local deviations, capture temperature gradients, and determine the lowest number of sensors required for reliable monitoring within a container or truck during perishable food transportation. Finally, [197] explored the factors that impact consumers' perceptions of traceability information carriers and found that the level of confidence in the information provided, perceived levels of convenience, influence on food quality and safety, influence on consumers' health and the environment, ethics, and privacy are among the key factors affecting consumers' perception of these technologies.

From 2010 to 2017, scholars have started to focus on the development of systems aiming at increasing sustainability and transparency in FSCs. For example, [112] analyzed the present situation of information systems to promote sustainability in FSCs and communications towards important stakeholders. It was found that information provision mostly concerns the single isolated business partner; therefore, technology use should be intensified to increase transparency, supply chain collaboration, and stimulate innovation and competitiveness. Based on [112], [198] investigated the specific issues of FSCs (e.g., information integrity, timeliness, and actuality) and argued that information sharing backed by information systems and IT is required to be able to respond to the wide variety of information needed by diverse chain actors, consumers, and the government.

In [199], a comprehensive literature review of food traceability challenges was conducted, and several technologies for traceability were identified, including external tags, chemical marking, physical marking, DNA markers, GIS, GPS, and EDI. Another review was also made by [200], who examined the current advancements in RFID in the food sector and concluded that this technology improves traceability of food products, monitors the condition of their processing conditions throughout the FSC stages, increases process efficiency, and provides consumers, government agencies, and customs officers with accurate information for real-time tracking of foods. The next paper on the path was authored by [201], who investigated the notion of virtualization in the FSC from the IoT perspective and provided an architecture to develop supporting information systems. The adoption of IoT makes the FSC a self-adaptive system in which smart products function, make decisions, and learn autonomously. Finally, [202] suggested a food pre-warning system based on association rule mining and IoT to promptly monitor all sensory data of the entire FSC and automatically pre-warn. The proposed system aimed to enable managers in food manufacturing companies to detect food safety risks early, support decision-making, and guarantee food safety and quality.

From 2018 to 2021, two different branches are plainly formed. The left branch comprises eight primary studies discussing the potentials and challenges of adopting blockchain technology in the FSC to ensure food quality and safety. [17] reviewed the possibilities of blockchain technology for ensuring authenticity and traceability in the FSC. Blockchain is a valuable means of tracking traceability difficulties and assuring FSC visibility and transparency by chronologically securing data records from chemical analyses so they are hard to modify later. The next two papers, [51] and [15], investigated the role of blockchain to improve food traceability from different perspectives such as people, process, and performance. After [15], several sub-branches appear. [50], [203], and [204] examined the applications, challenges, and societal impacts of blockchain technology in the FSC. [205] examined the level of customer centricity in FSCs in the context of a traceability system and demonstrated that health, trust, quality, nutrition, and safety-related values are critical determinants for consumer acceptance of a traceability system. Finally, [206] explored several forms of "agri-food tech" digital models and assessed their function in the agri-food industry. 
The right branch contains five papers that dealt with the performance of digitalized FSCs and the role of new technologies to mitigate supply chains risks and the COVID-19 pandemic. [82] reviewed 84 academic papers from 2000 to 2017 to realize the level of analytics employed (descriptive, predictive, and prescriptive), the objectives of the sustainable agriculture supply chain, and the supply chain processes from where the data gathered, and the resources allocated for agriculture activities. Data analytics can manage the never-ending complicated difficulties in FSC systems and achieve food safety, food security, and environmental sustainability. In the next paper, [36] made a thorough overview of machine learning applications in the agri-food industry. According to the authors, these technological solutions maximize the overall efficiency of the FSC and solve the various difficulties encountered by farmers, including crop yield, soil condition, and disease control. Similarly, [207] argued that deployment of industry 4.0 technologies could be among the strategies necessary to mitigate the challenges brought by the COVID-19 pandemic, such as supply and demand risks, financial risks, logistical and infrastructural risks, and operational issues, etc. Finally, the last two papers, [208] and [209], examined the potential and challenges of digitalization and IoT adoption in the FSC. Therefore, recent papers at the end of the key-route main path revealed several emerging technologies that contribute to the development of sustainable FSCs, such as blockchain, data analytics, and machine learning.

\section{Conclusions, Research Implications, and Limitations}

\subsection{Conclusions}

The main purpose of this study was to summarize the literature surrounding technology-enabled FSCs and expand the current literature by noting numerous knowledge gaps for future research. Building on bibliometric techniques and content analysis of selected papers, we identified the most relevant themes in extant research and uncovered emergent and promising routes for future studies. To undertake the analysis, a collection of 2140 publications was selected and considered for the final review. The review results can be relevant to researchers actively investigating digitalization in the FSC. Despite the rising literature on technology-enabled FSCs, there is still a paucity of publications offering a comprehensive picture of the future advances of digitalization in the food industry, extending the understanding of the topic and filling the knowledge gap. As a result, our analysis aims to fulfill this objective by identifying numerous themes and research areas at the intersection of digitalization, FSCs, and sustainability. Several significant insights can be derived from this study.

First, the number of papers related to digital FSCs has substantially grown over 19752021 (until June). The journal-wise distribution of selected papers suggested that Journal of Cleaner Production, Sustainability, and PLOS One are the leading venues contributing to the literature pertaining to technology-enabled FSCs. Our analysis demonstrated these journals and their role in advancing digitalization in the food sector over the years. Concerning the global impact, North American and European countries are the most prolific. The present research offers some fascinating insights about the role of digital technologies to assist FSC operations and boost the efficiency and sustainability of food processes. In terms of productivity, Hobbs J.E. and Mangla S.K. are the most prolific authors. In terms of institutional contributions, Wageningen University \& Research is the most productive institution. The keywords analysis indicates that the sustainable development of FSCs rests on the integration of modern technologies like IoT, blockchain, GIS in agri-food firms. The embrace of digitalization allows real-time monitoring and control of FSC operations, ensuring food safety and quality and increasing consumer satisfaction. By means of digitalization, FSC partners can increase the efficiency of their operations, create new possibilities of interactions with consumers directly. Moreover, the integration of new technologies can generate new professions or businesses associated 
with digitalization. From the perspective of environmental sustainability, the influence of new technologies is significant due to their ability to lower resources (e.g., water, fertilizers, waste) use, support the transition toward the circular economy and mitigate climate change. Lastly, the analysis of the core content and the historical development of FSCs reveals five major research clusters and three critical periods for digitalization in the context of FSCs.

\subsection{Research Implications}

For scholars seeking to obtain an increased understanding of digitalization in the FSC, the main content of the pertinent literature was discovered using keyword frequency analysis. The main findings derived from the keyword co-occurrence network analysis are the in-depth examination of the role of ICT in supporting agriculture, ensuring food security, and achieving sustainable development goals. More recently, though, scholars have focused their attention on emerging technologies such as IoT, blockchain, and artificial intelligence. The digitalization of the FSC is predicted to add more value for agrifood firms and enhance their operations, such as cultivation, food processing, transportation, and traceability. To obtain better knowledge of research at the intersection of digitalization and the FSC, researchers may refer to the articles analyzed in this review to understand how the ongoing improvement in digitalization and the use of modern technologies has allowed the automation of supply chain processes from upstream to downstream and the increase of operational efficiencies. Furthermore, technological advances in FSCs such as IoT contribute to the development of data-rich systems in the food sector by increasing access to information related to crop yield, weather, and diseases.

Being mindful of the most prolific authors in the literature will enable potential researchers to forge new research collaborations, initiate further projects, and improve the overall quality of future academic endeavors. In addition, the keyword co-occurrence network analysis serves to expose the structure of themes and topics discussed in the area of digitalization and the FSC. Likewise, it makes it easier to discover the core content of digitalization research and reveals several knowledge gaps. The literature is mainly focused on three main themes: (1) ICT for agriculture and food security, (2) food waste and circular economy, and (3) IoT and blockchain applications in FSCs. Given the shifting global dynamics, conventional approaches of guaranteeing food security and safety will not be sufficient and sustainable alone. Therefore, it is essential to develop innovative food security systems that reduce food waste throughout the different stages of the FSC, including production, transportation, and distribution.

In the current digital era, the rising disruptive technologies such as IoT, blockchain, and AI are progressively affecting the modus operandi of the food industry, giving birth to data-driven, sustainable, and circular FSCs. The results from the keyword cooccurrence network also highlight the role of geographic information systems (GIS) to increase food exposure and the focus of research on FSCs in developing countries, including India and China. Overall, the favorable influence of digitalization may be realized if technologies are combined effectively and rationally. However, the advantages of digitalization do not come without technical, organizational, regulatory, and ethical issues. In this regard, scholars and practitioners should closely work together to enhance the technical aspects of technologies, strategize the effective guidelines for implementing each technology, and carefully plan their investments in smart and data-driven FSCs. To uncover the studies that play critical knowledge diffusion roles in technology-enabled FSCs, we conducted a key-route main path analysis. The path systematically exhibits three research development cycles, including the earlier focus on RFID applications for food traceability, the development of systems for sustainable and transparent FSC, and the potentials of cutting-edge technologies like blockchain, big data analytics, and machine learning in the FSC. 
In conclusion, the present work adopts an objective, rigorous, and useful approach to synthesize related research themes and identify various avenues for further research. To the authors' best knowledge, this is the first effort to study the intellectual structure of technology-enabled FSCs and their role in developing a sustainable food sector based on a comprehensive set of journal articles published over nearly five decades. Our results will be beneficial for researchers and practitioners to gain an increased understanding of the current status of research at the intersection of digitalization and the FSC, and our suggestions for future works will enlighten them on the research gaps that require further attention.

\subsection{Limitations}

The analysis of research related to technology-enabled FSCs offers many new insights and considerably contributes to the literature, documenting the development of academic output, leading journals, authors, academic institutions, and contributing countries. However, several shortcomings are noticeable in this investigation. While the sample of selected articles is comprehensive, it is not exhaustive, and the dataset might be biased due to the filtering criteria. As is commonly done in review-based studies, our focus was on scholarly and English-speaking journal publications, eliminating potentially intriguing and important research being produced in other sources (e.g., books, conference proceedings) or languages. Moreover, it is vital to emphasize that our review includes academic results, and the classification by region or affiliation area does not enable us to make conclusions on the existing state of technology-enabled FSCs or their development in a certain nation. Building on the findings of this analysis, future research should broaden the context of this review and strengthen its findings by collecting additional data from other major academic databases such as the Web of Science. In addition, future bibliometric studies may include other important knowledge sources such as books, chapters, and conference papers to obtain new insights. Grouping research topics based on co-citation network or bibliographic coupling may be another interesting method in future bibliometric research.

Author Contributions: "Conceptualization, A.R. and M.I.; methodology, A.R, K.R. A.A..; software, K.R.; validation, A.R., S.Z., M.I. and M.G.; formal analysis, A.R, K.R., A.A.; investigation, A.R.; resources, K.R.; data curation, R.R.; writing-original draft preparation, A.R, K.R., A.A..; writingreview and editing, A.R.A.A.; visualization, K.R.; supervision, S.Z., M.I. and M.G.; project administration, S.Z.; funding acquisition, S.Z. All authors have read and agreed to the published version of the manuscript."

Funding: The research is funded by University of Malaya.

Data Availability Statement: Not applicable.

Acknowledgments: Not applicable.

Conflicts of Interest: The authors declare no conflict of interest.

\section{References}

1. Sufiyan, M.; Haleem, A.; Khan, S.; Khan, M.I. Evaluating Food Supply Chain Performance Using Hybrid Fuzzy MCDM Technique. Sustain. Prod. Consum. 2019, 20, 40-57.

2. Aqeel-Ur-Rehman; Abbasi, A.Z.; Islam, N.; Shaikh, Z.A. A Review of Wireless Sensors and Networks' Applications in Agriculture. Comput. Stand. Interfaces 2014, 36, 263-270, doi:10.1016/j.csi.2011.03.004.

3. Friha, O.; Ferrag, M.A.; Shu, L.; Maglaras, L.A.; Wang, X. Internet of Things for the Future of Smart Agriculture: A Comprehensive Survey of Emerging Technologies. IEEE CAA J Autom Sin. 2021, 8, 718-752.

4. Apaiah, R.K.; Hendrix, E.M. Design of a Supply Chain Network for Pea-Based Novel Protein Foods. J. Food Eng. 2005, 70, 383-391. 
5. Behzadi, G.; O'Sullivan, M.J.; Olsen, T.L.; Zhang, A. Agribusiness Supply Chain Risk Management: A Review of Quantitative Decision Models. Omega 2018, 79, 21-42.

6. UN World Population Prospects 2019.

7. Elijah, O.; Rahman, T.A.; Orikumhi, I.; Leow, C.Y.; Hindia, M.N. An Overview of Internet of Things (IoT) and Data Analytics in Agriculture: Benefits and Challenges. IEEE Internet Things J. 2018, 5, 3758-3773.

8. Tzounis, A.; Katsoulas, N.; Bartzanas, T.; Kittas, C. Internet of Things in Agriculture, Recent Advances and Future Challenges. Biosyst. Eng. 2017, 164, 31-48, doi:10.1016/j.biosystemseng.2017.09.007.

9. Agyabeng-Mensah, Y.; Ahenkorah, E.; Afum, E.; Dacosta, E.; Tian, Z. Green Warehousing, Logistics Optimization, Social Values and Ethics and Economic Performance: The Role of Supply Chain Sustainability. Int. J. Logist. Manag. 2020.

10. Manzini, R.; Accorsi, R. The New Conceptual Framework for Food Supply Chain Assessment. J. Food Eng. 2013, 115, 251-263.

11. Trivellas, P.; Malindretos, G.; Reklitis, P. Implications of Green Logistics Management on Sustainable Business and Supply Chain Performance: Evidence from a Survey in the Greek Agri-Food Sector. Sustainability 2020, 12, 10515.

12. Huan, M.; Ding, Z.; Li, S.; Zhang, C. Blockchain Consensus Mechanism Design for Food Safety Traceability.; Springer, 2021; pp. 620-627.

13. Zheng, M.; Zhang, S.; Zhang, Y.; Hu, B. Construct Food Safety Traceability System for People's Health Under the Internet of Things and Big Data. IEEE Access 2021, 9, 70571-70583.

14. Barbosa, M.W. Uncovering Research Streams on Agri-Food Supply Chain Management: A Bibliometric Study. Glob. Food Secur. 2021, 28, 100517.

15. Kayikci, Y.; Subramanian, N.; Dora, M.; Bhatia, M.S. Food Supply Chain in the Era of Industry 4.0: Blockchain Technology Implementation Opportunities and Impediments from the Perspective of People, Process, Performance, and Technology. Prod. Plan. Control 2020, 1-21.

16. Bermeo-Almeida, O.; Cardenas-Rodriguez, M.; Samaniego-Cobo, T.; Ferruzola-Gómez, E.; Cabezas-Cabezas, R.; Bazán-Vera, W. Blockchain in Agriculture: A Systematic Literature Review.; Springer, 2018; pp. 44-56.

17. Galvez, J.F.; Mejuto, J.C.; Simal-Gandara, J. Future Challenges on the Use of Blockchain for Food Traceability Analysis. TrAC Trends Anal. Chem. 2018, 107, 222-232.

18. Queiroz, M.M.; Telles, R.; Bonilla, S.H. Blockchain and Supply Chain Management Integration: A Systematic Review of the Literature. Supply Chain Manag. Int. J. 2019.

19. Rogerson, M.; Parry, G.C. Blockchain: Case Studies in Food Supply Chain Visibility. Supply Chain Manag. Int. J. 2020.

20. Gill, S.S.; Chana, I.; Buyya, R. IoT Based Agriculture as a Cloud and Big Data Service: The Beginning of Digital India. J. Organ. End User Comput. JOEUC 2017, 29, 1-23.

21. Kamble, S.S.; Gunasekaran, A.; Parekh, H.; Joshi, S. Modeling the Internet of Things Adoption Barriers in Food Retail Supply Chains. J. Retail. Consum. Serv. 2019, 48, 154-168.

22. Liu, S.; Guo, L.; Webb, H.; Ya, X.; Chang, X. Internet of Things Monitoring System of Modern Eco-Agriculture Based on Cloud Computing. IEEE Access 2019, 7, 37050-37058.

23. Lu, S.; Wang, X. Toward an Intelligent Solution for Perishable Food Cold Chain Management.; IEEE, 2016 ; pp. 852-856.

24. Rejeb, A.; Keogh, J.G.; Treiblmaier, H. Leveraging the Internet of Things and Blockchain Technology in Supply Chain Management. Future Internet 2019, 11, 161, doi:10.3390/fi11070161.

25. Khan, P.W.; Byun, Y.-C.; Park, N. IoT-Blockchain Enabled Optimized Provenance System for Food Industry 4.0 Using Advanced Deep Learning. Sensors 2020, 20, 2990.

26. Mondal, S.; Wijewardena, K.P.; Karuppuswami, S.; Kriti, N.; Kumar, D.; Chahal, P. Blockchain Inspired RFID-Based Information Architecture for Food Supply Chain. IEEE Internet Things J. 2019, 6, 5803-5813. 
27. Pincheira, M.; Vecchio, M.; Giaffreda, R.; Kanhere, S.S. Cost-Effective IoT Devices as Trustworthy Data Sources for a Blockchain-Based Water Management System in Precision Agriculture. Comput. Electron. Agric. 2021, 180, 105889.

28. Singh, A.; Kumari, S.; Malekpoor, H.; Mishra, N. Big Data Cloud Computing Framework for Low Carbon Supplier Selection in the Beef Supply Chain. J. Clean. Prod. 2018, 202, 139-149.

29. Tantalaki, N.; Souravlas, S.; Roumeliotis, M. Data-Driven Decision Making in Precision Agriculture: The Rise of Big Data in Agricultural Systems. J. Agric. Food Inf. 2019, 20, 344-380.

30. Zheng, J.; Yang, W. Design of a Precision Agriculture Leakage Seeding System Based on Wireless Sensors. Int. J. Online Eng. 2018, 14.

31. Zhou, Y.; Xie, Y.; Shao, L. Simulation of the Core Technology of a Greenhouse-Monitoring System Based on a Wireless Sensor Network. Int. J. Online Eng. 2016, 12.

32. Liakos, K.G.; Busato, P.; Moshou, D.; Pearson, S.; Bochtis, D. Machine Learning in Agriculture: A Review. Sensors 2018, 18, 2674.

33. Mercier, S.; Uysal, I. Neural Network Models for Predicting Perishable Food Temperatures along the Supply Chain. Biosyst. Eng. 2018, 171, 91-100.

34. Parsaeian, M.; Shahabi, M.; Hassanpour, H. Estimating Oil and Protein Content of Sesame Seeds Using Image Processing and Artificial Neural Network. J. Am. Oil Chem. Soc. 2020, 97, 691-702.

35. Shadrin, D.; Menshchikov, A.; Somov, A.; Bornemann, G.; Hauslage, J.; Fedorov, M. Enabling Precision Agriculture through Embedded Sensing with Artificial Intelligence. IEEE Trans. Instrum. Meas. 2019, 69, 4103-4113.

36. Sharma, R.; Kamble, S.S.; Gunasekaran, A.; Kumar, V.; Kumar, A. A Systematic Literature Review on Machine Learning Applications for Sustainable Agriculture Supply Chain Performance. Comput. Oper. Res. 2020, 119, 104926.

37. Hsu, T.-C.; Yang, H.; Chung, Y.-C.; Hsu, C.-H. A Creative IoT Agriculture Platform for Cloud Fog Computing. Sustain. Comput. Inform. Syst. 2020, 28, 100285.

38. Jinbo, C.; Xiangliang, C.; Han-Chi, F.; Lam, A. Agricultural Product Monitoring System Supported by Cloud Computing. Clust. Comput. 2019, 22, 8929-8938.

39. Zamora-Izquierdo, M.A.; Santa, J.; Martínez, J.A.; Martínez, V.; Skarmeta, A.F. Smart Farming IoT Platform Based on Edge and Cloud Computing. Biosyst. Eng. 2019, 177, 4-17.

40. Sharma, R.; Kamble, S.S.; Gunasekaran, A. Big GIS Analytics Framework for Agriculture Supply Chains: A Literature Review Identifying the Current Trends and Future Perspectives. Comput. Electron. Agric. 2018, 155, 103-120.

41. Korošak, Ž.; Suhadolnik, N.; Pleteršek, A. The Implementation of a Low Power Environmental Monitoring and Soil Moisture Measurement System Based on UHF RFID. Sensors 2019, 19, 5527.

42. Cancela, J.J.; González, X.P.; Vilanova, M.; Mirás-Avalos, J.M. Water Management Using Drones and Satellites in Agriculture 2019.

43. Mahroof, K.; Omar, A.; Rana, N.P.; Sivarajah, U.; Weerakkody, V. Drone as a Service (DaaS) in Promoting Cleaner Agricultural Production and Circular Economy for Ethical Sustainable Supply Chain Development. J. Clean. Prod. 2021, 287, 125522.

44. Rivera, M.A.; Pizam, A. Advances in Hospitality Research:“From Rodney Dangerfield to Aretha Franklin.” Int. J. Contemp. Hosp. Manag. 2015.

45. Liu, Y.; Ma, X.; Shu, L.; Hancke, G.P.; Abu-Mahfouz, A.M. From Industry 4.0 to Agriculture 4.0: Current Status, Enabling Technologies, and Research Challenges. IEEE Trans. Ind. Inform. 2020, 17, 4322-4334.

46. Abdollahi, A.; Rejeb, K.; Rejeb, A.; Mostafa, M.M.; Zailani, S. Wireless Sensor Networks in Agriculture: Insights from Bibliometric Analysis. Sustainability 2021, 13, 12011. 
47. Ben-Daya, M.; Hassini, E.; Bahroun, Z. Internet of Things and Supply Chain Management: A Literature Review. Int. J. Prod. Res. 2019, 57, 4719-4742.

48. Ben-Daya, M.; Hassini, E.; Bahroun, Z.; Banimfreg, B.H. The Role of Internet of Things in Food Supply Chain Quality Management: A Review. Qual. Manag. J. 2020, 28, 17-40.

49. Bouzembrak, Y.; Klüche, M.; Gavai, A.; Marvin, H.J. Internet of Things in Food Safety: Literature Review and a Bibliometric Analysis. Trends Food Sci. Technol. 2019, 94, 54-64.

50. Nurgazina, J.; Pakdeetrakulwong, U.; Moser, T.; Reiner, G. Distributed Ledger Technology Applications in Food Supply Chains: A Review of Challenges and Future Research Directions. Sustainability 2021, 13, 4206.

51. Feng, H.; Wang, X.; Duan, Y.; Zhang, J.; Zhang, X. Applying Blockchain Technology to Improve Agri-Food Traceability: A Review of Development Methods, Benefits and Challenges. J. Clean. Prod. 2020, 260, 121031.

52. Misra, N.; Dixit, Y.; Al-Mallahi, A.; Bhullar, M.S.; Upadhyay, R.; Martynenko, A. IoT, Big Data and Artificial Intelligence in Agriculture and Food Industry. IEEE Internet Things J. 2020.

53. Duan, J.; Zhang, C.; Gong, Y.; Brown, S.; Li, Z. A Content-Analysis Based Literature Review in Blockchain Adoption within Food Supply Chain. Int. J. Environ. Res. Public. Health 2020, 17, 1784.

54. Niknejad, N.; Ismail, W.; Bahari, M.; Hendradi, R.; Salleh, A.Z. Mapping the Research Trends on Blockchain Technology in Food and Agriculture Industry: A Bibliometric Analysis. Environ. Technol. Innov. 2020, 101272.

55. Jin, C.; Bouzembrak, Y.; Zhou, J.; Liang, Q.; van den Bulk, L.M.; Gavai, A.; Liu, N.; van den Heuvel, L.J.; Hoenderdaal, W.; Marvin, H.J. Big Data in Food Safety-A Review. Curr. Opin. Food Sci. 2020.

56. Vernier, C.; Loeillet, D.; Thomopoulos, R.; Macombe, C. Adoption of ICTs in Agri-Food Logistics: Potential and Limitations for Supply Chain Sustainability. Sustainability 2021, 13, 6702.

57. Lezoche, M.; Hernandez, J.E.; Díaz, M. del M.E.A.; Panetto, H.; Kacprzyk, J. Agri-Food 4.0: A Survey of the Supply Chains and Technologies for the Future Agriculture. Comput. Ind. 2020, 117, 103187.

58. Wahyuni, H.; Vanany, I.; Ciptomulyono, U. Food Safety and Halal Food in the Supply Chain: Review and Bibliometric Analysis. J. Ind. Eng. Manag. 2019, 12, 373-391, doi:10.3926/jiem.2803.

59. Aria, M.; Cuccurullo, C. Bibliometrix: An R-Tool for Comprehensive Science Mapping Analysis. J. Informetr. 2017, 11, 959975, doi:10.1016/j.joi.2017.08.007.

60. Fahimnia, B.; Sarkis, J.; Davarzani, H. Green Supply Chain Management: A Review and Bibliometric Analysis. Int. J. Prod. Econ. 2015, 162, 101-114, doi:10.1016/j.ijpe.2015.01.003.

61. Cullen, J.G. Educating Business Students About Sustainability: A Bibliometric Review of Current Trends and Research Needs. J. Bus. Ethics 2017, 145, 429-439, doi:10.1007/s10551-015-2838-3.

62. Marvuglia, A.; Havinga, L.; Heidrich, O.; Fonseca, J.; Gaitani, N.; Reckien, D. Advances and Challenges in Assessing Urban Sustainability: An Advanced Bibliometric Review. Renew. Sustain. Energy Rev. 2020, 124, 109788, doi:10.1016/j.rser.2020.109788.

63. Kamran, M.; Khan, H.U.; Nisar, W.; Farooq, M.; Rehman, S.-U. Blockchain and Internet of Things: A Bibliometric Study. Comput. Electr. Eng. 2020, 81, doi:10.1016/j.compeleceng.2019.106525.

64. Rejeb, A.; Treiblmaier, H.; Rejeb, K.; Zailani, S. Blockchain Research in Healthcare: A Bibliometric Review and Current Research Trends. J. Data Inf. Manag. 2021, doi:10.1007/s42488-021-00046-2.

65. Haleem, A.; Khan, M.I.; Khan, S.; Jami, A.R. Research Status in Halal: A Review and Bibliometric Analysis. Mod. Supply Chain Res. Appl. 2020, 2, 23-41, doi:10.1108/MSCRA-06-2019-0014.

66. Mostafa, M.M. A Knowledge Domain Visualization Review of Thirty Years of Halal Food Research: Themes, Trends and Knowledge Structure. Trends Food Sci. Technol. 2020, 99, 660-677, doi:10.1016/j.tifs.2020.03.022. 
67. Rejeb, A.; Rejeb, K.; Zailani, S. Are Halal Food Supply Chains Sustainable: A Review And Bibliometric Analysis. J. Foodserv. Bus. Res. 2021, 0, 1-42, doi:10.1080/15378020.2021.1883214.

68. Lee, P.-C.; Su, H.-N. Investigating the Structure of Regional Innovation System Research through Keyword Co-Occurrence and Social Network Analysis. Innovation 2010, 12, 26-40, doi:10.5172/impp.12.1.26.

69. An, X.Y.; Wu, Q.Q. Co-Word Analysis of the Trends in Stem Cells Field Based on Subject Heading Weighting. Scientometrics 2011, 88, 133-144, doi:10.1007/s11192-011-0374-1.

70. Cobo, M.J.; López-Herrera, A.G.; Herrera-Viedma, E.; Herrera, F. Science Mapping Software Tools: Review, Analysis, and Cooperative Study among Tools. J. Am. Soc. Inf. Sci. Technol. 2011, 62, 1382-1402, doi:https://doi.org/10.1002/asi.21525.

71. Feng, Y.; Zhu, Q.; Lai, K.-H. Corporate Social Responsibility for Supply Chain Management: A Literature Review and Bibliometric Analysis. J. Clean. Prod. 2017, 158, 296-307, doi:10.1016/j.jclepro.2017.05.018.

72. Kaffash, S.; Marra, M. Data Envelopment Analysis in Financial Services: A Citations Network Analysis of Banks, Insurance Companies and Money Market Funds. Ann. Oper. Res. 2017, 253, 307-344, doi:10.1007/s10479-016-2294-1.

73. Liu, J.S.; Lu, L.Y.Y.; Ho, M.H.-C. A Few Notes on Main Path Analysis. Scientometrics 2019, 119, 379-391, doi:10.1007/s11192019-03034-x.

74. Liu, J.S.; Lu, L.Y.Y. An Integrated Approach for Main Path Analysis: Development of the Hirsch Index as an Example. J. Am. Soc. Inf. Sci. Technol. 2012, 63, 528-542, doi:https://doi.org/10.1002/asi.21692.

75. Foncubierta-Rodríguez, A.; Müller, H.; Depeursinge, A. Retrieval of High-Dimensional Visual Data: Current State, Trends and Challenges Ahead. Multimed. Tools Appl. 2014, 69, 539-567, doi:10.1007/s11042-012-1327-2.

76. Maflahi, N.; Thelwall, M. When Are Readership Counts as Useful as Citation Counts? Scopus versus Mendeley for LIS Journals. J. Assoc. Inf. Sci. Technol. 2016, 67, 191-199, doi:10.1002/asi.23369.

77. Bradford, S.C. Sources of Information on Specific Subjects. Engineering 1934, 137, 85-86.

78. Govindan, K. Sustainable Consumption and Production in the Food Supply Chain: A Conceptual Framework. Int. J. Prod. Econ. 2018, 195, 419-431, doi:10.1016/j.ijpe.2017.03.003.

79. Bernardi, D.P.D.; Bertello, A.; Venuti, D.F.; Zardini, D.A. Knowledge Transfer Driving Community-Based Business Models towards Sustainable Food-Related Behaviours: A Commons Perspective. Knowl. Manag. Res. Pract. 2019, 0, 1-8, doi:10.1080/14778238.2019.1664271.

80. Mohapatra, A.G.; Keswani, B.; Lenka, S.K. ICT Specific Technological Changes in Precision Agriculture Environment. Int. J. Comput. Sci. Mob. Appl. 2018, 1-16.

81. Brewster, C.; Roussaki, I.; Kalatzis, N.; Doolin, K.; Ellis, K. IoT in Agriculture: Designing a Europe-Wide Large-Scale Pilot. IEEE Commun. Mag. 2017, 55, 26-33, doi:10.1109/MCOM.2017.1600528.

82. Kamble, S.S.; Gunasekaran, A.; Gawankar, S.A. Achieving Sustainable Performance in a Data-Driven Agriculture Supply Chain: A Review for Research and Applications. Int. J. Prod. Econ. 2020, 219, 179-194, doi:10.1016/j.ijpe.2019.05.022.

83. Klerkx, L.; Jakku, E.; Labarthe, P. A Review of Social Science on Digital Agriculture, Smart Farming and Agriculture 4.0: New Contributions and a Future Research Agenda. NJAS - Wagening. J. Life Sci. 2019, 90-91, doi:10.1016/j.njas.2019.100315.

84. Tzounis, A.; Katsoulas, N.; Bartzanas, T.; Kittas, C. Internet of Things in Agriculture, Recent Advances and Future Challenges. Biosyst. Eng. 2017, 164, 31-48.

85. Wolfert, S.; Ge, L.; Verdouw, C.; Bogaardt, M.-J. Big Data in Smart Farming - A Review. Agric. Syst. 2017, 153, 69-80, doi:10.1016/j.agsy.2017.01.023.

86. Galvez, J.F.; Mejuto, J.C.; Simal-Gandara, J. Future Challenges on the Use of Blockchain for Food Traceability Analysis. TrAC - Trends Anal. Chem. 2018, 107, 222-232, doi:10.1016/j.trac.2018.08.011.

87. Salah, K.; Nizamuddin, N.; Jayaraman, R.; Omar, M. Blockchain-Based Soybean Traceability in Agricultural Supply Chain. IEEE Access 2019, 7, 73295-73305, doi:10.1109/ACCESS.2019.2918000. 
88. Christiaensen, L.; Rutledge, Z.; Taylor, J.E. Viewpoint: The Future of Work in Agri-Food. Food Policy 2021, 99, 101963, doi:10.1016/j.foodpol.2020.101963.

89. Di Vaio, A.; Boccia, F.; Landriani, L.; Palladino, R. Artificial Intelligence in the Agri-Food System: Rethinking Sustainable Business Models in the COVID-19 Scenario. Sustainability 2020, 12, 4851, doi:10.3390/su12124851.

90. Borrello, M.; Caracciolo, F.; Lombardi, A.; Pascucci, S.; Cembalo, L. Consumers' Perspective on Circular Economy Strategy for Reducing Food Waste. Sustainability 2017, 9, 141, doi:10.3390/su9010141.

91. Halloran, A.; Clement, J.; Kornum, N.; Bucatariu, C.; Magid, J. Addressing Food Waste Reduction in Denmark. Food Policy 2014, 49, 294-301, doi:10.1016/j.foodpol.2014.09.005.

92. Maina, S.; Kachrimanidou, V.; Koutinas, A. A Roadmap towards a Circular and Sustainable Bioeconomy through Waste Valorization. Curr. Opin. Green Sustain. Chem. 2017, 8, 18-23, doi:10.1016/j.cogsc.2017.07.007.

93. Li, X.; Wu, P.; Shen, G.Q.; Wang, X.; Teng, Y. Mapping the Knowledge Domains of Building Information Modeling (BIM): A Bibliometric Approach. Autom. Constr. 2017, 84, 195-206, doi:10.1016/j.autcon.2017.09.011.

94. Borner, K.; Chen, C.; Boyack, K.W. Visualizing Knowledge Domains. Annu. Rev. Inf. Sci. Technol. ARIST 2003, 37, $179-255$.

95. Cambrosio, A.; Limoges, C.; Courtial, J.; Laville, F. Historical Scientometrics? Mapping over 70 Years of Biological Safety Research with Coword Analysis. Scientometrics 2005, 27, 119-143, doi:10.1007/bf02016546.

96. Kriegel, H.-P.; Kröger, P.; Sander, J.; Zimek, A. Density-Based Clustering. WIREs Data Min. Knowl. Discov. 2011, 1, 231-240, doi:10.1002/widm.30.

97. Fernandez-Alles, M.; Ramos-Rodríguez, A. Intellectual Structure of Human Resources Management Research: A Bibliometric Analysis of the Journal Human Resource Management, 1985-2005. J. Am. Soc. Inf. Sci. Technol. 2009, 60, 161-175, doi:10.1002/asi.20947.

98. Rejeb, A.; Simske, S.; Rejeb, K.; Treiblmaier, H.; Zailani, S. Internet of Things Research in Supply Chain Management and Logistics: A Bibliometric Analysis. Internet Things 2020, 12, 100318, doi:10.1016/j.iot.2020.100318.

99. Garrone, P.; Melacini, M.; Perego, A. Opening the Black Box of Food Waste Reduction. Food Policy 2014, 46, 129-139, doi:10.1016/j.foodpol.2014.03.014.

100. McMichael, P. Value-Chain Agriculture and Debt Relations: Contradictory Outcomes. Third World Q. 2013, 34, 671-690, doi:10.1080/01436597.2013.786290.

101. Pereira, L.M. Cassava Bread in Nigeria: The Potential of ‘Orphan Crop' Innovation for Building More Resilient Food Systems. Int. J. Technol. Glob. 2017, 8, 97-115, doi:10.1504/IJTG.2017.088958.

102. Tahir, I.S.A.; Mustafa, H.M.; Idris, A.A.M.; Elhashimi, A.M.A.; Hassan, M.K.; Fadul, E.M.; Kurmut, A.M.A.; Eltayeb, S.M.; Meheesi, S.; Hassan, A.O.; et al. Enhancing Wheat Production and Food Security in Sudan through Scaling up Improved Technologies Using Innovation Platforms. Int. J. Agric. Sustain. 2020, 376-388, doi:10.1080/14735903.2020.1787639.

103. Long, T.B.; Blok, V.; Coninx, I. Barriers to the Adoption and Diffusion of Technological Innovations for Climate-Smart Agriculture in Europe: Evidence from the Netherlands, France, Switzerland and Italy. J. Clean. Prod. 2016, 112, 9-21, doi:10.1016/j.jclepro.2015.06.044.

104. Henchion, M.; Hayes, M.; Mullen, A.M.; Fenelon, M.; Tiwari, B. Future Protein Supply and Demand: Strategies and Factors Influencing a Sustainable Equilibrium. Foods 2017, 6, 1-21, doi:10.3390/foods6070053.

105. Kyriacou, M.C.; Rouphael, Y. Towards a New Definition of Quality for Fresh Fruits and Vegetables. Sci. Hortic. 2018, 234, 463-469, doi:10.1016/j.scienta.2017.09.046.

106. Lehmann, R.J.; Reiche, R.; Schiefer, G. Future Internet and the Agri-Food Sector: State-of-the-Art in Literature and Research. Comput. Electron. Agric. 2012, 89, 158-174, doi:10.1016/j.compag.2012.09.005.

107. El Bilali, H.; Allahyari, M.S. Transition towards Sustainability in Agriculture and Food Systems: Role of Information and Communication Technologies. Inf. Process. Agric. 2018, 5, 456-464, doi:10.1016/j.inpa.2018.06.006. 
108. Manocha, P.; Srai, J.S. Exploring Environmental Supply Chain Innovation in M\&a. Sustain. Switz. 2020, 12, 1-15, doi:10.3390/su122310105.

109. Kaur, H. Modelling Internet of Things Driven Sustainable Food Security System. Benchmarking 2019, 28, 1740-1760, doi:10.1108/BIJ-12-2018-0431.

110. Alamar, M.D.C.; Falagán, N.; Aktas, E.; Terry, L.A. Minimising Food Waste: A Call for Multidisciplinary Research. J. Sci. Food Agric. 2018, 98, 8-11, doi:10.1002/jsfa.8708.

111. Notarnicola, B.; Sala, S.; Anton, A.; McLaren, S.J.; Saouter, E.; Sonesson, U. The Role of Life Cycle Assessment in Supporting Sustainable Agri-Food Systems: A Review of the Challenges. J. Clean. Prod. 2017, 140, 399-409, doi:10.1016/j.jclepro.2016.06.071.

112. Wognum, P.M.; Bremmers, H.; Trienekens, J.H.; Van Der Vorst, J.G.A.J.; Bloemhof, J.M. Systems for Sustainability and Transparency of Food Supply Chains - Current Status and Challenges. Adv. Eng. Inform. 2011, 25, 65-76, doi:10.1016/j.aei.2010.06.001.

113. Civancik-Uslu, D.; Puig, R.; Ferrer, L.; Fullana-i-Palmer, P. Influence of End-of-Life Allocation, Credits and Other Methodological Issues in LCA of Compounds: An in-Company Circular Economy Case Study on Packaging. J. Clean. Prod. 2019, 212, 925-940, doi:10.1016/j.jclepro.2018.12.076.

114. Borrello, M.; Lombardi, A.; Pascucci, S.; Cembalo, L. The Seven Challenges for Transitioning into a Bio-Based Circular Economy in the Agri-Food Sector. Recent Pat. Food Nutr. Agric. 2016, 8, 39-47, doi:10.2174/221279840801160304143939.

115. Jarvie, H.P.; Flaten, D.; Sharpley, A.N.; Kleinman, P.J.A.; Healy, M.G.; King, S.M. Future Phosphorus: Advancing New 2D Phosphorus Allotropes and Growing a Sustainable Bioeconomy. J. Environ. Qual. 2019, 48, 1145-1155, doi:10.2134/jeq2019.03.0135.

116. Valenti, F.; Porto, S.M.C.; Dale, B.E.; Liao, W. Spatial Analysis of Feedstock Supply and Logistics to Establish Regional Biogas Power Generation: A Case Study in the Region of Sicily. Renew. Sustain. Energy Rev. 2018, 97, 50-63, doi:10.1016/j.rser.2018.08.022.

117. Fassio, F.; Tecco, N. Circular Economy for Food: A Systemic Interpretation of 40 Case Histories in the Food System in Their Relationships with SDGs. Systems 2019, 7, 43, doi:10.3390/systems7030043.

118. Khoifin, K.; Nimsai, S. Investigating Traceability Costs and Benefits in Food Supply Chain: Case Study in Serang City, Indonesia. Int. J. Supply Chain Manag. 2018, 7, 153.

119. Sun, S.; Wang, X. Promoting Traceability for Food Supply Chain with Certification. J. Clean. Prod. 2019, 217, 658-665.

120. Xiang, B. Study on Safety Management of Food Traceability Based on Food Supply Chain. J Food Sci Technol $2015,8,394-397$.

121. Yadav, S.; Garg, D.; Luthra, S. Analysing Challenges for Internet of Things Adoption in Agriculture Supply Chain Management. Int. J. Ind. Syst. Eng. 2020, 36, 73-97.

122. Kamble, S.S.; Gunasekaran, A.; Gawankar, S.A. Achieving Sustainable Performance in a Data-Driven Agriculture Supply Chain: A Review for Research and Applications. Int. J. Prod. Econ. 2020, 219, 179-194.

123. Zhang, C.; Li, S.; Qu, J. Safety Traceability System of Characteristic Food Based on RFID and EPC Internet of Things. Int. J. Online Biomed. Eng. 2019, 15.

124. Astill, J.; Dara, R.A.; Campbell, M.; Farber, J.M.; Fraser, E.D.; Sharif, S.; Yada, R.Y. Transparency in Food Supply Chains: A Review of Enabling Technology Solutions. Trends Food Sci. Technol. 2019, 91, 240-247.

125. Tian, F. A Supply Chain Traceability System for Food Safety Based on HACCP, Blockchain \& Internet of Things.; IEEE, 2017; pp. 1-6.

126. Bhutta, M.N.M.; Ahmad, M. Secure Identification, Traceability and Real-Time Tracking of Agricultural Food Supply During Transportation Using Internet of Things. IEEE Access 2021, 9, 65660-65675. 
127. Tsang, Y.P.; Choy, K.L.; Wu, C.H.; Ho, G.T.S.; Lam, H.Y. Blockchain-Driven IoT for Food Traceability with an Integrated Consensus Mechanism. IEEE Access 2019, 7, 129000-129017.

128. Moudoud, H.; Cherkaoui, S.; Khoukhi, L. An IoT Blockchain Architecture Using Oracles and Smart Contracts: The Use-Case of a Food Supply Chain.; IEEE, 2019; pp. 1-6.

129. Awan, S.H.; Ahmad, S.; Khan, Y.; Safwan, N.; Qurashi, S.S.; Hashim, M.Z. A Combo Smart Model of Blockchain with the Internet of Things (IoT) for the Transformation of Agriculture Sector. Wirel. Pers. Commun. 2021, 1-17.

130. Banerjee, M.; Lee, J.; Choo, K.-K.R. A Blockchain Future for Internet of Things Security: A Position Paper. Digit. Commun. Netw. 2018, 4, 149-160.

131. Jin, S.; Zhang, Y.; Xu, Y. Amount of Information and the Willingness of Consumers to Pay for Food Traceability in China. Food Control 2017, 77, 163-170.

132. Kshetri, N. 1 Blockchain's Roles in Meeting Key Supply Chain Management Objectives. Int. J. Inf. Manag. 2018,39 , 80-89.

133. Anisi, M.H.; Abdul-Salaam, G.; Abdullah, A.H. A Survey of Wireless Sensor Network Approaches and Their Energy Consumption for Monitoring Farm Fields in Precision Agriculture. Precis. Agric. 2015, 16, 216-238.

134. Yin, H.; Cao, Y.; Marelli, B.; Zeng, X.; Mason, A.J.; Cao, C. Soil Sensors and Plant Wearables for Smart and Precision Agriculture. Adv. Mater. 2021, 33, 2007764.

135. Befort, C.A.; Nazir, N.; Perri, M.G. Prevalence of Obesity among Adults from Rural and Urban Areas of the United States: Findings from NHANES (2005-2008). J. Rural Health 2012, 28, 392-397.

136. Jia, P.; Cheng, X.; Xue, H.; Wang, Y. Applications of Geographic Information Systems (GIS) Data and Methods in Obesityrelated Research. Obes. Rev. 2017, 18, 400-411.

137. Lucan, S.C.; Mitra, N. The Food Environment and Dietary Intake: Demonstrating a Method for GIS-Mapping and PolicyRelevant Research. J. Public Health 2012, 20, 375-385.

138. McGuirt, J.T.; Jilcott Pitts, S.B.; Gustafson, A. Association between Spatial Access to Food Outlets, Frequency of Grocery Shopping, and Objectively-Assessed and Self-Reported Fruit and Vegetable Consumption. Nutrients 2018, 10, 1974.

139. Barnes, T.L.; Bell, B.A.; Freedman, D.A.; Colabianchi, N.; Liese, A.D. Do People Really Know What Food Retailers Exist in Their Neighborhood? Examining GIS-Based and Perceived Presence of Retail Food Outlets in an Eight-County Region of South Carolina. Spat. Spatio-Temporal Epidemiol. 2015, 13, 31-40.

140. Barnes, T.L.; Colabianchi, N.; Freedman, D.A.; Bell, B.A.; Liese, A.D. Do GIS-Derived Measures of Fast Food Retailers Convey Perceived Fast Food Opportunities? Implications for Food Environment Assessment. Ann. Epidemiol. 2017, $27,27-34$.

141. Moore, L.V.; Diez Roux, A.V.; Nettleton, J.A.; Jacobs Jr, D.R. Associations of the Local Food Environment with Diet Qualitya Comparison of Assessments Based on Surveys and Geographic Information Systems: The Multi-Ethnic Study of Atherosclerosis. Am. J. Epidemiol. 2008, 167, 917-924.

142. Moore, L.V.; Roux, A.V.D.; Brines, S. Comparing Perception-Based and Geographic Information System (GIS)-Based Characterizations of the Local Food Environment. J. Urban Health 2008, 85, 206-216.

143. Thornton, L.E.; Pearce, J.R.; Kavanagh, A.M. Using Geographic Information Systems (GIS) to Assess the Role of the Built Environment in Influencing Obesity: A Glossary. Int. J. Behav. Nutr. Phys. Act. 2011, 8, 1-9.

144. Van Meter, E.; Lawson, A.; Colabianchi, N.; Nichols, M.; Hibbert, J.; Porter, D.; Liese, A. Spatial Accessibility and Availability Measures and Statistical Properties in the Food Environment. Spat. Spatio-Temporal Epidemiol. 2011, 2, 35-47.

145. Moore, L.V.; Diez Roux, A.V.; Nettleton, J.A.; Jacobs, D.R.; Franco, M. Fast-Food Consumption, Diet Quality, and Neighborhood Exposure to Fast Food: The Multi-Ethnic Study of Atherosclerosis. Am. J. Epidemiol. 2009, 170, 29-36.

146. Sharkey, J.R. Measuring Potential Access to Food Stores and Food-Service Places in Rural Areas in the US. Am. J. Prev. Med. 2009, 36, S151-S155. 
147. Balcetis, E.; Cole, S.; Bisi, A. Near and Nothing to It: Perceived Proximity Improves Exercise by Increasing Feasibility Appraisals. Motiv. Sci. 2015, 1, 203.

148. Sugovic, M.; Turk, P.; Witt, J.K. Perceived Distance and Obesity: It's What You Weigh, Not What You Think. Acta Psychol. (Amst.) 2016, 165, 1-8.

149. Baldock, K.L.; Paquet, C.; Howard, N.J.; Coffee, N.T.; Taylor, A.W.; Daniel, M. Correlates of Discordance between Perceived and Objective Distances to Local Fruit and Vegetable Retailers. Int. J. Environ. Res. Public. Health 2019, 16, 1262.

150. Balcetis, E. Approach and Avoidance as Organizing Structures for Motivated Distance Perception. Emot. Rev. 2016, 8, 115128.

151. Chrisinger, B.W.; King, A.C.; Hua, J.; Saelens, B.E.; Frank, L.D.; Conway, T.L.; Cain, K.L.; Sallis, J.F. How Well Do Seniors Estimate Distance to Food? The Accuracy of Older Adults' Reported Proximity to Local Grocery Stores. Geriatrics $2019,4,11$.

152. Kärmeniemi, M.; Lankila, T.; Ikäheimo, T.; Koivumaa-Honkanen, H.; Korpelainen, R. The Built Environment as a Determinant of Physical Activity: A Systematic Review of Longitudinal Studies and Natural Experiments. Ann. Behav. Med. 2018, 52, 239-251.

153. Mayne, S.L.; Auchincloss, A.H.; Michael, Y.L. Impact of Policy and Built Environment Changes on Obesity-related Outcomes: A Systematic Review of Naturally Occurring Experiments. Obes. Rev. 2015, 16, 362-375.

154. van der Velde, L.A.; Zitman, F.M.; Mackenbach, J.D.; Numans, M.E.; Kiefte-de Jong, J.C. The Interplay between Fast-Food Outlet Exposure, Household Food Insecurity, and Diet Quality in Disadvantaged Districts. Public Health Nutr. 2020, 1-20.

155. Caldwell, E.M.; Kobayashi, M.M.; DuBow, W.; Wytinck, S. Perceived Access to Fruits and Vegetables Associated with Increased Consumption. Public Health Nutr. 2009, 12, 1743-1750.

156. Giskes, K.; van Lenthe, Fj.; Kamphuis, Cbm.; Huisman, M.; Brug, J.; Mackenbach, J.P. Household and Food Shopping Environments: Do They Play a Role in Socioeconomic Inequalities in Fruit and Vegetable Consumption? A Multilevel Study among Dutch Adults. J. Epidemiol. Community Health 2009, 63, 113-120.

157. Pitts, S.B.J.; Keyserling, T.C.; Johnston, L.F.; Smith, T.W.; McGuirt, J.T.; Evenson, K.R.; Rafferty, A.P.; Gizlice, Z.; Garcia, B.A.; Ammerman, A.S. Associations between Neighborhood-Level Factors Related to a Healthful Lifestyle and Dietary Intake, Physical Activity, and Support for Obesity Prevention Polices among Rural Adults. J. Community Health 2015, 40, $276-284$.

158. Jia, P.; Xue, H.; Yin, L.; Stein, A.; Wang, M.; Wang, Y. Spatial Technologies in Obesity Research: Current Applications and Future Promise. Trends Endocrinol. Metab. 2019, 30, 211-223.

159. Baldock, K.L.; Paquet, C.; Howard, N.J.; Coffee, N.T.; Taylor, A.W.; Daniel, M. Are Perceived and Objective Distances to Fresh Food and Physical Activity Resources Associated with Cardiometabolic Risk? Int. J. Environ. Res. Public. Health 2018, $15,224$.

160. Bernsdorf, K.A.; Lau, C.J.; Andreasen, A.H.; Toft, U.; Lykke, M.; Glümer, C. Accessibility of Fast Food Outlets Is Associated with Fast Food Intake. A Study in the Capital Region of Denmark. Health Place 2017, 48, 102-110.

161. Cannuscio, C.C.; Hillier, A.; Karpyn, A.; Glanz, K. The Social Dynamics of Healthy Food Shopping and Store Choice in an Urban Environment. Soc. Sci. Med. 2014, 122, 13-20.

162. Chrisinger, B. A Mixed-Method Assessment of a New Supermarket in a Food Desert: Contributions to Everyday Life and Health. J. Urban Health 2016, 93, 425-437.

163. Cummins, S.; Flint, E.; Matthews, S.A. New Neighborhood Grocery Store Increased Awareness of Food Access but Did Not Alter Dietary Habits or Obesity. Health Aff. (Millwood) 2014, 33, 283-291.

164. Dubowitz, T.; Ghosh-Dastidar, M.; Cohen, D.A.; Beckman, R.; Steiner, E.D.; Hunter, G.P.; Flórez, K.R.; Huang, C.; Vaughan, C.A.; Sloan, J.C. Diet and Perceptions Change with Supermarket Introduction in a Food Desert, but Not Because of Supermarket Use. Health Aff. (Millwood) 2015, 34, 1858-1868.

165. Hillier, A.; Smith, T.E.; Whiteman, E.D.; Chrisinger, B.W. Discrete Choice Model of Food Store Trips Using National Household Food Acquisition and Purchase Survey (FoodAPS). Int. J. Environ. Res. Public. Health 2017, $14,1133$. 
166. Lehning, A.J.; Smith, R.J.; Dunkle, R.E. Age-Friendly Environments and Self-Rated Health: An Exploration of Detroit Elders. Res. Aging 2014, 36, 72-94.

167. Wen, M.; Hawkley, L.C.; Cacioppo, J.T. Objective and Perceived Neighborhood Environment, Individual SES and Psychosocial Factors, and Self-Rated Health: An Analysis of Older Adults in Cook County, Illinois. Soc. Sci. Med. 2006, 63, 2575-2590.

168. Cebrecos, A.; Díez, J.; Gullón, P.; Bilal, U.; Franco, M.; Escobar, F. Characterizing Physical Activity and Food Urban Environments: A GIS-Based Multicomponent Proposal. Int. J. Health Geogr. 2016, 15, 1-13.

169. Aggarwal, S.; Srivastava, M.K. Towards a Grounded View of Collaboration in Indian Agri-Food Supply Chains: A Qualitative Investigation. Br. Food J. 2016.

170. Parwez, S. A Conceptual Model for Integration of Indian Food Supply Chains. Glob. Bus. Rev. 2016, 17, 834-850.

171. Singh, R.K.; Luthra, S.; Mangla, S.K.; Uniyal, S. Applications of Information and Communication Technology for Sustainable Growth of SMEs in India Food Industry. Resour. Conserv. Recycl. 2019, 147, 10-18.

172. Akhtar, P.; Tse, Y.K.; Khan, Z.; Rao-Nicholson, R. Data-Driven and Adaptive Leadership Contributing to Sustainability: Global Agri-Food Supply Chains Connected with Emerging Markets. Int. J. Prod. Econ. 2016, 181, 392-401.

173. Luthra, S.; Mangla, S.K.; Garg, D.; Kumar, A. Internet of Things (IoT) in Agriculture Supply Chain Management: A Developing Country Perspective. In Emerging Markets from a Multidisciplinary Perspective; Springer, 2018; pp. $209-220$.

174. Luthra, S.; Mangla, S.K. When Strategies Matter: Adoption of Sustainable Supply Chain Management Practices in an Emerging Economy's Context. Resour. Conserv. Recycl. 2018, 138, 194-206.

175. Mirkovski, K.; Davison, R.M.; Martinsons, M.G. The Effects of Trust and Distrust on ICT-Enabled Information Sharing in Supply Chains: Evidence from Small-and Medium-Sized Enterprises in Two Developing Economies. Int. J. Logist. Manag. 2019.

176. Balaji, M.; Arshinder, K. Modeling the Causes of Food Wastage in Indian Perishable Food Supply Chain. Resour. Conserv. Recycl. 2016, 114, 153-167.

177. Huang, L.; Liu, P. Key Technologies and Alogrithms' Application in Agricultural Food Supply Chain Tracking System in eCommerce.; Springer, 2013; pp. 269-281.

178. Zhuo, N.; Ji, C.; Yin, N. Supply Chain Integration and Resilience in China's Pig Sector: Case Study Evidences from Emerging Institutional Arrangements. Environ. Sci. Pollut. Res. 2021, 28, 8310-8322.

179. Vranda, J.; Tavishi, T.; Narayanan, G.B. Unlocking Technology Adoption for a Robust Food Supply Chain: Evidence from Indian Food Processing Sector. Экономический Журнал Высшей Школь Экономики 2021, 25.

180. Anthony, V.M.; Ferroni, M. Agricultural Biotechnology and Smallholder Farmers in Developing Countries. Curr. Opin. Biotechnol. 2012, 23, 278-285.

181. Jain, A.; Singh, N.; Kumari, S.; Khan, S. Bioentrepreneurship in Agricultural Biotechnology. In Bioentrepreneurship and Transferring Technology Into Product Development; IGI Global, 2021; pp. 183-200.

182. Kakkar, A. A Blockchain Technology Solution to Enhance Operational Efficiency of Rice Supply Chain for Food Corporation of India.; Springer, 2019; pp. 24-31.

183. Kumar, M.V.; Iyengar, N.C.S.N.; Goar, V. Employing Blockchain in Rice Supply Chain Management. In Advances in Information Communication Technology and Computing; Springer, 2021; pp. 451-461.

184. Li, Y.; Chu, X.; Tian, D.; Feng, J.; Mu, W. A Traceability Architecture for the Fresh Food Supply Chain Based on Blockchain Technology in China.; Springer, 2020; pp. 347-358.

185. Praveen, P.; Shaik, M.A.; Kumar, T.S.; Choudhury, T. Smart Farming: Securing Farmers Using Block Chain Technology and IOT. In Blockchain Applications in IoT Ecosystem; Springer, 2021; pp. 225-238. 
186. Tian, F. An Agri-Food Supply Chain Traceability System for China Based on RFID \& Blockchain Technology.; IEEE, 2016; pp. $1-6$.

187. Chhabra, V.; Rajan, P.; Chopra, S. User Acceptance of New Technology in Mandatory Adoption Scenario for Food Distribution in India. Int. J. Food Syst. Dyn. 2020, 11, 153-170.

188. Chauhan, A.; Kaur, H.; Yadav, S.; Jakhar, S.K. A Hybrid Model for Investigating and Selecting a Sustainable Supply Chain for Agri-Produce in India. Ann. Oper. Res. 2020, 290, 621-642.

189. Joshi, S.; Singh, R.K.; Sharma, M. Sustainable Agri-Food Supply Chain Practices: Few Empirical Evidences from a Developing Economy. Glob. Bus. Rev. 2020, 0972150920907014.

190. Memon, S.U.R.; Pawase, V.R.; Pavase, T.R.; Soomro, M.A. Investigation of COVID-19 Impact on the Food and Beverages Industry: China and India Perspective. Foods 2021, 10, 1069.

191. Salin, V. Information Technology in Agri-Food Supply Chains. Int. Food Agribus. Manag. Rev. 1998, 1, 329-334, doi:10.1016/S1096-7508(99)80003-2.

192. Opara, L.U.; Mazaud, F. Food Traceability from Field to Plate. Outlook Agric. 2001, 30, 239-247, doi:10.5367/000000001101293724.

193. Mangina, E.; Vlachos, I.P. The Changing Role of Information Technology in Food and Beverage Logistics Management: Beverage Network Optimisation Using Intelligent Agent Technology. J. Food Eng. 2005, 70, 403-420, doi:10.1016/j.jfoodeng.2004.02.044.

194. Taylor, D.H.; Fearne, A. Towards a Framework for Improvement in the Management of Demand in Agri-food Supply Chains. Supply Chain Manag. Int. J. 2006, 11, 379-384, doi:10.1108/13598540610682381.

195. Kumar, P.; Reinitz, H. w.; Simunovic, J.; Sandeep, K. p.; Franzon, P. d. Overview of RFID Technology and Its Applications in the Food Industry. J. Food Sci. 2009, 74, R101-R106, doi:10.1111/j.1750-3841.2009.01323.x.

196. Jedermann, R.; Ruiz-Garcia, L.; Lang, W. Spatial Temperature Profiling by Semi-Passive RFID Loggers for Perishable Food Transportation. Comput. Electron. Agric. 2009, 65, 145-154, doi:10.1016/j.compag.2008.08.006.

197. Chrysochou, P.; Chryssochoidis, G.; Kehagia, O. Traceability Information Carriers. The Technology Backgrounds and Consumers' Perceptions of the Technological Solutions. Appetite 2009, 53, 322-331, doi:10.1016/j.appet.2009.07.011.

198. Trienekens, J.H.; Wognum, P.M.; Beulens, A.J.M.; van der Vorst, J.G.A.J. Transparency in Complex Dynamic Food Supply Chains. Adv. Eng. Inform. 2012, 26, 55-65, doi:10.1016/j.aei.2011.07.007.

199. Bosona, T.; Gebresenbet, G. Food Traceability as an Integral Part of Logistics Management in Food and Agricultural Supply Chain. Food Control 2013, 33, 32-48, doi:10.1016/j.foodcont.2013.02.004.

200. Costa, C.; Antonucci, F.; Pallottino, F.; Aguzzi, J.; Sarriá, D.; Menesatti, P. A Review on Agri-Food Supply Chain Traceability by Means of RFID Technology. Food Bioprocess Technol. 2013, 6, 353-366, doi:10.1007/s11947-012-0958-7.

201. Verdouw, C.N.; Wolfert, J.; Beulens, A.J.M.; Rialland, A. Virtualization of Food Supply Chains with the Internet of Things. J. Food Eng. 2016, 176, 128-136, doi:10.1016/j.jfoodeng.2015.11.009.

202. Wang, J.; Yue, H. Food Safety Pre-Warning System Based on Data Mining for a Sustainable Food Supply Chain. Food Control 2017, 73, 223-229, doi:10.1016/j.foodcont.2016.09.048.

203. Vivaldini, M. Blockchain in Operations for Food Service Distribution: Steps before Implementation. Int. J. Logist. Manag. 2021, doi:10.1108/IJLM-07-2020-0299.

204. Mangla, S.K.; Kazancoglu, Y.; Ekinci, E.; Liu, M.; Özbiltekin, M.; Sezer, M.D. Using System Dynamics to Analyze the Societal Impacts of Blockchain Technology in Milk Supply Chainsrefer. Transp. Res. Part E Logist. Transp. Rev. 2021, 149, doi:10.1016/j.tre.2021.102289.

205. Anastasiadis, F.; Apostolidou, I.; Michailidis, A. Food Traceability: A Consumer-centric Supply Chain Approach on Sustainable Tomato. Foods 2021, 10, doi:10.3390/foods10030543. 
206. Vlachopoulou, M.; Ziakis, C.; Vergidis, K.; Madas, M. Analyzing AgriFood-Tech e-Business Models. Sustainability 2021, 13, 5516, doi:10.3390/su13105516.

207. Sharma, R.; Shishodia, A.; Kamble, S.; Gunasekaran, A.; Belhadi, A. Agriculture Supply Chain Risks and COVID-19: Mitigation Strategies and Implications for the Practitioners. Int. J. Logist. Res. Appl. 2020, 0, 1-27, doi:10.1080/13675567.2020.1830049.

208. Bahn, R.A.; Yehya, A.A.K.; Zurayk, R. Digitalization for Sustainable Agri-Food Systems: Potential, Status, and Risks for the Mena Region. Sustain. Switz. 2021, 13, doi:10.3390/su13063223.

209. Aamer, A.M.; Al-Awlaqi, M.A.; Affia, I.; Arumsari, S.; Mandahawi, N. The Internet of Things in the Food Supply Chain: Adoption Challenges. Benchmarking 2021, doi:10.1108/BIJ-07-2020-0371. 